\title{
Sleep Deprivation and Caffeine Treatment Potentiate Photic Resetting of the Master Circadian Clock in a Diurnal Rodent
}

\author{
๑DPawan Kumar Jha, ${ }^{1,4,5,6}$ Hanan Bouâouda, ${ }^{1}$ Sylviane Gourmelen, ${ }^{1}$ Stephanie Dumont, ${ }^{1}$ Fanny Fuchs, ${ }^{2}$ \\ Yannick Goumon, ${ }^{3}$ Patrice Bourgin, ${ }^{2}{ }^{-}$Andries Kalsbeek, ${ }^{4,5,6}$ and ${ }^{-}$Etienne Challet ${ }^{1,6}$ \\ ${ }^{1}$ Regulation of Circadian Clocks Team, Institute of Cellular and Integrative Neurosciences, ${ }^{2}$ Light, Rhythms and Sleep Homeostasis Team, CIRCSom-CHU, \\ and ${ }^{3}$ Molecular Determinants of Pain Team, Institute of Cellular and Integrative Neurosciences, UPR3212, CNRS, University of Strasbourg, 67084 \\ Strasbourg, France, ${ }^{4}$ Department of Endocrinology and Metabolism, Academic Medical Center, University of Amsterdam, 1012 WX, Amsterdam, The \\ Netherlands, ${ }^{5} \mathrm{Hyp}$ othalamic Integration Mechanisms, Netherlands Institute for Neuroscience, $1105 \mathrm{BA}$, Amsterdam-Zuidoost, The Netherlands, and \\ ${ }^{6}$ International Associated Laboratory LIA1061, Understanding the Neural Basis of Diurnality, CNRS, 67084 Strasbourg, France
}

Circadian rhythms in nocturnal and diurnal mammals are primarily synchronized to local time by the light/dark cycle. However, nonphotic factors, such as behavioral arousal and metabolic cues, can also phase shift the master clock in the suprachiasmatic nuclei (SCNs) and/or reduce the synchronizing effects of light in nocturnal rodents. In diurnal rodents, the role of arousal or insufficient sleep in these functions is still poorly understood. In the present study, diurnal Sudanian grass rats, Arvicanthis ansorgei, were aroused at night by sleep deprivation (gentle handling) or caffeine treatment that both prevented sleep. Phase shifts of locomotor activity were analyzed in grass rats transferred from a light/dark cycle to constant darkness and aroused in early night or late night. Early night, but not late night, sleep deprivation induced a significant phase shift. Caffeine on its own induced no phase shifts. Both sleep deprivation and caffeine treatment potentiated light-induced phase delays and phase advances in response to a $30 \mathrm{~min}$ light pulse, respectively. Sleep deprivation in early night, but not late night, potentiated light-induced c-Fos expression in the ventral SCN. Caffeine treatment in midnight triggered c-Fos expression in dorsal SCN. Both sleep deprivation and caffeine treatment potentiated light-induced c-Fos expression in calbindincontaining cells of the ventral SCN in early and late night. These findings indicate that, in contrast to nocturnal rodents, behavioral arousal induced either by sleep deprivation or caffeine during the sleeping period potentiates light resetting of the master circadian clock in diurnal rodents, and activation of calbindin-containing suprachiasmatic cells may be involved in this effect.

Key words: behavioral arousal; circadian rhythms; phase shift; photic resetting; suprachiasmatic nucleus

Significance Statement

Arousing stimuli have the ability to regulate circadian rhythms in mammals. Behavioral arousal in the sleeping period phase shifts the master clock in the suprachiasmatic nuclei and/or slows down the photic entrainment in nocturnal animals. How these stimuli act in diurnal species remains to be established. Our study in a diurnal rodent, the Grass rat, indicates that sleep deprivation in the early rest period induces phase delays of circadian locomotor activity rhythm. Contrary to nocturnal rodents, both sleep deprivation and caffeine-induced arousal potentiate the photic entrainment in a diurnal rodent. Such enhanced light-induced circadian responses could be relevant for developing chronotherapeutic strategies.

\section{Introduction}

The phasing of the cycle of sleep and wakefulness with respect to day and night is one of the key rhythmic components that divides ani-

Received Oct. 19, 2016; revised Feb. 22, 2017; accepted March 9, 2017.

Author contributions: P.K.J., A.K., and E.C. designed research; P.K.J., H.B., S.G., and S.D. performed research; P.K.J. and H.B. contributed unpublished reagents/analytic tools; P.K.J., H.B., S.D., and F.F. analyzed data; P.K.J., H.B., Y.G., P.B., A.K., and E.C. wrote the paper.

Our studies were supported by doctoral fellowships from the "Neurotime" Erasmus Mundus Program, European Doctoral College of University of Strasbourg and Eurometropolis of Strasbourg (P.K.J.), recurrent grants from Centre National de la Recherche Scientifique, University of Strasbourg (E.C.), and the University of Amsterdam (A.K.). We thank Dr. Paul Chu Sin Chung for help with EEG surgery, and Ludivine Robin for assistance in EEG analysis. We also thank Virginie Chavant for her help with HPLC assays. In addition, we thank Dominique Ciocca and Nicolas Lethenet mals into night-active (nocturnal) and day-active (diurnal) species. There has been considerable research on circadian rhythms in nocturnal rodents with regard to the synchronizing properties of light and other cues, including behavioral arousal and metabolic factors.

(Chronobiotron Platform, UMS3415, CNRS, University of Strasbourg) for having bred the Sudanian grass rats. Also we thank Professor Paul Pévet for continuous support.

The authors declare no competing financial interests.

Correspondence should be addressed to Pawan Kumar Jha, Regulation of Circadian Clocks Team, Institute of Cellular and Integrative Neurosciences, UPR3212, Centre National de la Recherche Scientifique (CNRS), University of Strasbourg, 67084 Strasbourg, France. E-mail: kj.pawan@gmail.com.

DOI:10.1523/JNEUROSCI.3241-16.2017

Copyright $\odot 2017$ the authors $\quad 0270-6474 / 17 / 374343-16 \$ 15.00 / 0$ 
Diurnal species, however, have been studied much less compared with nocturnal rodents, especially for nonphotic synchronizing factors. Since the temporal organization of sleep and arousal is inverted between nocturnal and diurnal animals, we asked how arousal synchronizes circadian rhythms in diurnal animals.

In addition to the sleep/wake cycle, a number of other daily rhythms, such as the feeding/fasting cycle and hormonal rhythms, are oppositely phased relative to the light/dark cycle between nocturnal and diurnal mammals (Jha et al., 2015). However, the central clock in the suprachiasmatic nucleus (SCN) of the hypothalamus, which regulates rhythmicity of most behavioral and physiological parameters, is most active at the same astronomical time in these two categories of mammals. For instance, glucose utilization and firing rate in the SCN are high during the day and low at night in both diurnal and nocturnal animals (Smale et al., 2003). The genesis of circadian rhythmicity is based on the rhythmic expression of core clock genes such as Pers (Per1-3), Crys (Cry1-2), Bmal1, Clock, and nuclear receptors Rev-erb $\alpha / \beta$ and Ror $\alpha / \beta$ (Mohawk et al., 2012). Temporal patterns of expression of most of these clock genes in the SCN are similar in nocturnal and diurnal species (Albrecht et al., 1997; Shearman et al., 2000; Mrosovsky et al., 2001; Caldelas et al., 2003).

The molecular clock machinery is reset by environmental cues. In particular, light can synchronize the SCN neurons via a cascade of transcriptional activation. Both diurnal and nocturnal species are most sensitive to the synchronizing effects of light at night. Within nocturnal and diurnal species the mechanisms underlying photic resetting are essentially similar in terms of temporal sensitivity and the direction of light-induced phase shifts (Challet, 2007). As a rule, light exposure during the early and late subjective night elicits phase delays and advances, respectively (Daan and Pittendrigh, 1976; Slotten et al., 2005). In addition to light, numerous nonphotic factors have the ability to reset the phase and period of the SCN clock and influence its photic resetting (Mrosovsky, 1996; Challet and Pévet, 2003; Challet, 2007). Some of these factors are based on involuntary arousal in the resting period. Notably, it has been found that sleep deprivation induced by gentle handling during the resting period leads to phase advances of locomotor activity rhythm in the nocturnal Syrian hamster (Antle and Mistlberger, 2000). Moreover, this treatment attenuates light-induced phase delays in both hamsters and mice (Mistlberger et al., 1997; Challet et al., 2001; van Diepen et al., 2014). On the other hand, systemic administration of the adenosine antagonist caffeine (CAF) during the usual resting period induces arousal without shifting the SCN clock in Syrian hamster, whereas it blocks light-induced phase shifts (Antle et al., 2001; Vivanco et al., 2013).

Most studies concerning nonphotic entrainment have been performed in nocturnal hamsters and mice. To study behavioral arousal as a possible nonphotic synchronizing agent in diurnal rodents, we first examined whether sleep deprivation or caffeine-induced arousal affects the phase-shifting effect of light in the Sudanian grass rat (Arvicanthis ansorgei). The magnitude of sleep deprivation and caffeine-induced arousal was quantified by electroencephalogram (EEG) combined with electromyogram (EMG) recording. Second, we used c-Fos as a marker of neuronal activation to investigate the molecular mechanisms of entrainment; we also examined c-Fos expression in the SCNs of behaviorally aroused animals. Third, we phenotyped the neurons expressing c-Fos in the SCN. Fourth, to better understand the neurochemical basis and assess the state of arousal, we measured serotonin, adenosine, and caffeine concentrations in the SCN and midbrain raphe area of animals, aroused or not, by caffeine and sleep deprivation.

\section{Materials and Methods}

Experiments were performed in accordance with the US National Institutes of Health Guide for the Care and Use of Laboratory Animals (1996) and French National Law (implementing the European Directive 2010/ 63/EU) and were approved by the Regional Ethical Committee of Strasbourg for Animal Experimentation and the French Ministry of Higher Education and Research (approval \#01050.02).

\section{Animals and housing conditions}

Male Sudanian grass rats (A. ansorgei), 3-4 months old, were obtained from a local breeding colony (Chronobiotron platform, UMS3415, CNRS, University of Strasbourg) in Strasbourg, weighing 100-150 g at the beginning of the study. During baseline, animals were maintained at $23^{\circ} \mathrm{C}$ under a $12 \mathrm{~h}$ light/dark (LD) cycle (light intensity during light and dark periods (red light on) was, respectively, 200 and $<3$ lux). Lights went on at 07:00 A.M. and off at 07:00 P.M. defining zeitgeber time 0 (ZT0) and ZT12, respectively. During the actimetry experiments, animals were housed individually in Plexiglas cages $(35 \times 22 \times 40 \mathrm{~cm})$ equipped with running wheels (diameter, $34 \mathrm{~cm}$ ) with ad libitum food and water in the LD cycle. Wheel-running activity was continuously recorded and stored in $5 \mathrm{~min}$ bins by Vital-View (Mini-Mitter). After a period of 2 weeks, animals were transferred into constant darkness (DD; red light, $<3$ lux). Animals included in the present study displayed bimodal patterns of diurnal locomotor activity.

\section{EEG and EMG surgery}

A classic set of EEG and EMG electrodes was implanted according to methods previously described and adapted to A. ansorgei (Hubbard et al., 2015). The electrodes were implanted under deep anesthesia (intraperitoneal injection of ketamine $80 \mathrm{mg} / \mathrm{kg}$ and xylazine $7 \mathrm{mg} / \mathrm{kg}$ ), then soldered to a connector and cemented to the skull before the skin was sutured. Holes were drilled in the skull, and animals were implanted with two epidural EEG electrodes (frontal, $2.0 \mathrm{~mm}$ lateral to middle, $2.0 \mathrm{~mm}$ anterior to bregma; parietal, $2.0 \mathrm{~mm}$ lateral to middle, $2.0 \mathrm{~mm}$ anterior to lambda) and one reference electrode (Hubbard et al., 2015). In addition, two EMG electrodes were inserted into the neck muscles along the back of the skull in a manner that they did not touch each other. Thereafter, EEG electrodes were cemented to the skull and the skin was sutured where needed. Animals were allowed to recover from surgery and habituate to the recording conditions for a minimum of 2 weeks.

\section{Experimental design}

Experiment 1: assessment of EEG and EMG changes in response to sleep deprivation and caffeine treatment. We assessed the actual sleep loss during an early and late subjective night of sleep deprivation or caffeine treatment. A first set of animals $(n=6)$ was transferred to DD for $2 \mathrm{~d}$, and EEG and EMG were recorded using commercial Compumedics hardware (Neuvo 64-512 Channel EEG HD-LTM) and software (Profusion PSG 4 Software and Neuroscan Curry 7). For sleep deprivation, on the first day of DD, animals were left undisturbed [baseline condition used as the control (CTR) procedure]. On the second day, they were sleep deprived by gentle handling during $4 \mathrm{~h}$ in early subjective night from projected circadian time 12 (CT12; defined as projected time of lights off during the previous light/dark cycle) to CT16 $(n=6)$. Animals were allowed to synchronize to the $12 \mathrm{~h} \mathrm{LD} \mathrm{cycle} \mathrm{for} \mathrm{a} \mathrm{few} \mathrm{days} \mathrm{before} \mathrm{repeat-}$ ing the same procedures in $\mathrm{DD}$ as above, except that sleep deprivation occurred in late subjective night from CT16 to CT20 $(n=5)$.

Similarly, the animals were exposed for $2 \mathrm{~d}$ to DD to analyze the effect of caffeine administration. Continuous sleep recordings were performed on the first day of DD as baseline and on the second day of DD to analyze the effects of intraperitoneal injection at CT14 of either CAF $(30 \mathrm{mg} / \mathrm{kg}$ in $0.9 \%$ saline; C0750, Sigma-Aldrich) or vehicle (VEH; 0.9\% saline). Animals were allowed to synchronize to the $12 \mathrm{~h} \mathrm{LD}$ cycle for a few days before repeating the same procedures in $\mathrm{DD}$ in a crossover design of caffeine and vehicle treatment at CT18 $(n=4)$.

Experiment 2: early night sleep deprivation. We next studied the circadian clock resetting by sleep deprivation (SD) in early night. On the first day of DD, a second set of animals $(n=24)$ was transferred to new cages 
(without running wheel) at projected CT12. Twelve of them were sleep deprived by gentle handling (Hubbard et al., 2015) from CT12 to CT16. The remaining 12 animals were kept undisturbed as CTRs. After sleep deprivation, half of the animals from both the sleep-deprived and control groups were subjected to a $30 \mathrm{~min}$ light pulse of fluorescent white light (200 lux at the level of animals; "Light") at CT16, while the other animals were kept in darkness ("Dark"). Thereafter, all animals were transferred back to their home cages. Thus, there were four groups (each $n=6$ ), as follows: (1) CTR plus Dark; (2) SD plus Dark; (3) CTR plus Light; and (4) $\mathrm{SD}$ plus Light. Then, animals were left undisturbed in DD for $8 \mathrm{~d}$ before being resynchronized to the $\mathrm{LD}$ cycle for at least 2 weeks.

Thereafter, to investigate the molecular responses, the 24 animals that were used in the above-mentioned actimetry experiment were divided into four groups again ( $n=6$ per group, as indicated above, but newly randomized) and transferred to DD where they were sleep deprived and exposed to a light pulse as described above. Animals were killed under a dim red light ( $<3$ lux at the level of animals; TL-D 18W Red SLV, Philips) $1 \mathrm{~h}$ after the end of sleep deprivation in the Dark groups and $30 \mathrm{~min}$ after light exposure in the Light groups (i.e., CT17).

Experiment 3: late night sleep deprivation. A third set of animals $(n=$ 24) was used here. The procedures for this study were the same as for experiment 2, except that the sleep deprivation period was from CT16 to CT20, while animals from groups 3 and 4 were exposed to a light pulse at CT20. Then, animals were left undisturbed in DD for $8 \mathrm{~d}$ before being resynchronized to $\mathrm{LD}$ for at least 2 weeks. The treatments were repeated in DD as above, except that brains were sampled at CT21 on the first day of DD.

Experiment 4: morning caffeine treatments. A fourth set of animals ( $n=$ 24) was used for this experiment. Treatments were administered on the first day of DD. Each animal received an intraperitoneal injection of CAF or VEH at CT0 followed $2 \mathrm{~h}$ after the injection by a $30 \mathrm{~min}$ light pulse (Light) or no light (Dark) at CT2. Thus, there were four groups $(n=6)$. As follows: (1) VEH plus Dark; (2) CAF plus Dark; (3) VEH plus Light; and (4) CAF plus Light. Then, animals were left undisturbed in DD for $8 \mathrm{~d}$ before being resynchronized to LD for at least 2 weeks.

Experiment 5: midday caffeine treatments. A fifth set of animals $(n=24)$ was used here. The procedure for this treatment was the same as for experiment 4, except that the timing of CAF or VEH injection was at CT6 and that the animals in groups 3 and 4 were exposed to a light pulse at CT8.

Experiment 6: early night caffeine treatments. The procedure and animals for this treatment were the same as in experiment 4, except that the timing of the CAF and VEH injections was at CT14 and the animals in groups 3 and 4 were exposed to light pulses at CT16. Then, animals were left undisturbed in DD for $8 \mathrm{~d}$ before being resynchronized to the LD cycle for at least 2 weeks.

To investigate the molecular responses, the same animals used for actimetry were divided into four groups again $(n=6$ per group, as indicated above, but newly randomized) and transferred to DD. Animals were treated with CAF or VEH at CT14. In addition, animals in groups 3 and 4 were exposed to a light pulse at CT16. Animals were killed under a dim red light ( $<3$ lux at the level of animals; TL-D 18W Red SLV, Philips) $3 \mathrm{~h}$ after CAF treatment (i.e., CT17 on the first day of DD).

Experiment 7: midnight caffeine treatments. The procedure and animals for this treatment were the same as for experiment 5 , except that the timing of the CAF and VEH injection was at CT18 and animals of groups 3 and 4 were exposed to a light pulse at CT20. Then, animals were left undisturbed in $\mathrm{DD}$ for $8 \mathrm{~d}$ before being resynchronized to LD for at least 2 weeks. The animals used for actimetry were then treated again as above and were killed at CT21 on the first day of DD.

\section{Analysis of behavioral data}

For sleep scoring, EEG and EMG signals were amplified, filtered, and analog-to-digital converted to $256 \mathrm{~Hz}$. Each $10 \mathrm{~s}$ epoch was scored by two independent scorers as wake or sleep by visual inspection of the EEG and EMG signals without knowledge of the recording condition and according to criteria previously validated in a study first characterizing the sleep/wake cycle of A. ansorgei (Hubbard et al., 2015). Time spent in each vigilance state was then calculated for each condition.
Wheel-running activity was continuously recorded and stored in 5 min bins by Vital-View (Mini-Mitter). All parameters for wheel-running activity were determined with ClockLab Software (ActiMetrics). The beginning and end of activity at approximately ZT/CT0 and approximately ZT/CT12 were considered as onset and offset, respectively. Although similar trends were observed both for activity onsets and offsets, the amplitudes of the shifts were larger for offsets than for onsets (data not shown). Therefore, throughout the experiments, we selected offset points (approximately ZT12/CT12) for the calculation of phase shifts. The magnitude and the direction of elicited phase shifts were calculated by linear regression (ClockLab) encompassing the $7 \mathrm{~d}$ before the sleep deprivation or caffeine treatments and the $7 \mathrm{~d}$ after it, excluding transitory cycles. Phase-shift magnitudes were calculated by considering the interval between the two fitted lines by a researcher blind to experimental procedures. Phase shifts in response to sleep deprivation, caffeine treatment, sleep deprivation plus light or caffeine treatment plus light were assessed using the Aschoff type II procedure (Refinetti, 2006). The freerunning period of wheel-running activity rhythm was determined by $\chi^{2}$ periodogram analysis (ClockLab).

\section{Immunohistochemistry}

Animals used for immunohistochemistry were deeply anesthetized with a high dose of sodium pentobarbital $(150 \mathrm{mg} / \mathrm{kg}$, i.p.) and intracardially perfused with saline $(0.9 \% \mathrm{NaCl})$ followed by $4 \%$ paraformaldehyde in 0.1 м phosphate buffer, $\mathrm{pH}$ 7.4.

Each brain was rapidly removed and postfixed in the same fixative for $24 \mathrm{~h}$, then cryoprotected in $30 \%$ sucrose for $48 \mathrm{~h}$. Brains were frozen in isopentane at $-40^{\circ} \mathrm{C}$ and stored at $-80^{\circ} \mathrm{C}$. Coronal sections of $30 \mu \mathrm{m}$ through the SCN were prepared with a cryostat (CM 3000, Leica) and stored at $-20^{\circ} \mathrm{C}$ in Watson solution.

Single labeling for Fos within the suprachiasmatic nucleus. For c-Fos immunostaining, free-floating brain sections were washed in PBS, $\mathrm{pH}$ 7.4 , and incubated in a solution of $3 \% \mathrm{H}_{2} \mathrm{O}_{2}(30 \%$ hydrogen peroxide, Sigma-Aldrich) in PBS for 30 min. Brain sections were rinsed in PBS for 10 min three times and (1) were incubated in 10\% normal goat serum (Millipore Bioscience Research Reagents) in PBS with 0.3\% Tween-20 (Sigma-Aldrich) for $1 \mathrm{~h}$, followed by (2) an incubation with a rabbit polyclonal anti-c-Fos antibody (1:4000; SC-52, Santa Cruz Biotechnology) for $24 \mathrm{~h}$ at $4^{\circ} \mathrm{C}$, followed by (3) biotinylated secondary antibody for $2 \mathrm{~h}$ at room temperature (1:500; goat anti-rabbit in PBS with $0.3 \%$ Tween-T20, Vector Laboratories), followed by (4) avidin-biotin complex $(\mathrm{ABC})$ for $1 \mathrm{~h}$ at room temperature $(0.2 \%$ each for avidin and biotin solutions; ABC Vectastain Kit in PBS with $0.05 \%$ Tween-20, Vector Laboratories). Sections were then allowed to react in diaminobenzidine (DAB; $0.5 \mathrm{mg} / \mathrm{ml}$, Sigma-Aldrich) with $0.015 \% \mathrm{H}_{2} \mathrm{O}_{2}$ in tap water. In between each step after step 2, brain sections were rinsed three times for $10 \mathrm{~min}$ in PBS. Tissue sections were mounted onto gelatin-coated slides, dehydrated through a series of alcohol baths, soaked in toluene, and coverslipped with Eukitt (Chem-Lab). We performed the staining in one run for sleep deprivation and caffeine treatment experiments.

Double labeling for Fos and calbindin within the suprachiasmatic nucleus. To phenotype the Fos-immunoreactive (IR) neurons in the SCN, we performed double labeling of Fos and calbindin, based on the distinct pattern of c-Fos induction in the mid-SCN of animals in the sleepdeprived and caffeine-treated group in the dark and their topographic resemblance with the pattern of calbindin expression described in the SCN of Arvicanthis niloticus (Mahoney et al., 2000). Initially, brain sections were processed for $\mathrm{c}$-Fos using a nickel enhanced $\mathrm{DAB}$ procedure as described in the single labeling for c-Fos. After reaction with $\mathrm{ABC}$, tissue was reacted by mixing $\mathrm{DAB}(0.5 \mathrm{mg} / \mathrm{ml}), 0.015 \% \mathrm{H}_{2} \mathrm{O}_{2}$, and $2.5 \%$ nickel sulfate. Following the $\mathrm{c}$-Fos reaction, the tissue was rinsed and processed for the detection of calbindin immunoreactivity as follows: brain sections were incubated with a mouse monoclonal anti-calbindin-D-28k antibody (1:2000; C9848, Sigma-Aldrich) for $24 \mathrm{~h}$ at room temperature, followed by the same procedures as reported above for c-Fos single labeling (i.e., biotinylated secondary antibody, $\mathrm{ABC}$, and incubation with $\mathrm{DAB}$ without nickel sulfate). Tissue sections were mounted onto gelatincoated slides, dehydrated through a series of alcohol baths, soaked in toluene, and coverslipped with Eukitt (Chem-Lab). 


\section{Microscopic quantification}

A single section through the central SCN per animal was selected for quantification. Cells were visualized by using a DMRB Microscope (Leica Microsystems) equipped with a DP50 Digital Camera (Olympus France). Images were taken $(5 \times$ for single labeling and $20 \times$ for double labeling) standardizing all lighting parameters on the microscope and the camera software (Viewfinder Lite, Olympus) to ensure consistent stable lighting throughout the image capture. Quantifications were performed with ImageJ software (W.S. Rasband, National Institutes of Health). For single labeling, IR neurons within the SCN were quantified within rectangular templates placed in dorsal $(0.18 \times 0.13 \mathrm{~mm} ; 0.11 \times 0.1 \mathrm{~mm})$ and ventral $(0.26 \times 0.22 \mathrm{~mm})$ regions by an observer unaware of the experimental conditions. For double labeling, the number of calbindin neurons colocalizing with c-Fos was counted in the dorsoventral area of SCN by an observer blind to the experiments and only those calbindin-positive cells that presented a clear double staining of c-Fos (black nucleus) and calbindin (light brown soma) were included as colocalizing neurons.

Serotonin and adenosine content in SCN and midbrain of sleep-deprived and caffeine-treated animals. To conduct this experiment, a sixth set of animals $(n=24)$ were maintained in a $12 \mathrm{~h}$ LD cycle for 2 weeks and transferred to DD. On the first day of DD, 12 animals were transferred to new cages (without running wheel) at CT12, and 6 of these 12 animals were sleep deprived by gentle handling (Hubbard et al., 2015) between CT12 and CT16. At the same time, the remaining 12 animals were selected for caffeine-induced arousal or VEH treatment. Treatments were administered on the first day of DD. Each animal received an intraperitoneal injection of CAF or VEH at CT14. All animals were killed at CT17 by decapitation after an overdose of sodium pentobarbital $(150 \mathrm{mg} / \mathrm{kg}$, i.p.). The brains were rapidly removed. Thereafter, $\mathrm{SCN}$ region and midbrain were microdissected visually and stored at $-80^{\circ} \mathrm{C}$.

Serotonin and 5-HIAA in SCN of animals treated with fluoxetine. To activate the brain serotonergic system, additional animals maintained in $12 \mathrm{~h} \mathrm{LD}$ cycle were injected with fluoxetine hydrochloride $(10 \mathrm{mg} / \mathrm{kg}$; F132, Sigma-Aldrich), a serotonin reuptake inhibitor $(n=5)$, or vehicle ( $0.9 \%$ saline, $n=5)$ at ZT9. Three hours later (i.e., ZT12), animals were killed by decapitation after an overdose of sodium pentobarbital (150 $\mathrm{mg} / \mathrm{kg}$, i.p.), and SCN samples were microdissected as above. The dosage and timing of sampling were determined according to previous studies in rats (Bourdeaux et al., 1998).

SCN, midbrain, and plasma preparation for liquid chromatography-tandem mass spectrometry analysis. Microdissections of SCN and midbrain raphe were homogenized in ultrapure water and centrifuged at 15,000 $\times$ g. Plasma was centrifuged at $18,000 \times g$. Ten picomoles of D3-caffeine, C5-adenosine, D4-serotonin, and D5-5-hydroxyindoleacetic acid (5-HIAA) internal standards were added to each sample before the AccQTag treatment. Only serotonin [5-hydroxytryptamine (5-HT)] and D4-serotonin were derivatized on amine functions. The AccQTag derivation protocol was performed according to the manufacturer recommendations (Waters). Concentrations of total soluble protein in the extracts were determined using Bradford method (Protein Assay, Bio-Rad).

Liquid chromatography-tandem mass spectrometry instrumentation and analytical conditions. Liquid chromatography analyses were performed to quantify the presence of caffeine, adenosine, and serotonin. Analyses were performed on a Dionex Ultimate 3000 High-Pressure Liquid Chromatography system (Thermo Scientific) coupled with a triple-quadrupole Endura (Thermo Scientific). The system was controlled by Xcalibur Software version 2.0 (Thermo Scientific). Ten microliters of each sample was loaded into an Accucore RP-MS column (reference 17626-102130; $100 \times 2.1 \mathrm{~mm}, 2.6 \mu \mathrm{m}$, Thermo Scientific) heated at $35^{\circ} \mathrm{C}$. All molecules and their corresponding deuterated compounds were eluted by applying a gradient of buffer $\mathrm{A}$ and buffer B. Buffer A corresponded to $\mathrm{H}_{2} \mathrm{O} 99.9 \% /$ formic acid $0.1 \%(\mathrm{v} / \mathrm{v})$, whereas buffer B was ACN 99.9\%/formic acid $0.1 \%(\mathrm{v} / \mathrm{v})$. A linear gradient of $20-85 \%$ of solvent B at $400 \mu \mathrm{l} / \mathrm{min}$ during $2.5 \mathrm{~min}$ was applied and followed by a washing step $(0.5 \mathrm{~min}$ at $85 \%$ of solvent $\mathrm{B})$ and an equilibration step (1 min of $20 \%$ of buffer B).

Qualitative analysis and quantification was performed in the selected reaction monitoring (SRM) mode. For ionization, $3500 \mathrm{~V}$ of liquid junction voltage and $292^{\circ} \mathrm{C}$ capillary temperature was applied. The selectivity for both Q1 and Q3 was set to $0.7 \mathrm{Da}$ (FWHM). The collision gas pressure of Q2 was set at 2 mTorr of argon. For all molecules, the selection of the monitored transitions and the optimization of the collision energy (CE) were first determined. The transitions and the corresponding CEs used for SRM mode were the following: charge/mass ratio $(\mathrm{m} / \mathrm{z}) 195.2 \rightarrow \mathrm{m} / \mathrm{z}$ $138.1(\mathrm{CE}=28 \mathrm{eV})$ for caffeine; $\mathrm{m} / \mathrm{z} 198.2 \rightarrow \mathrm{m} / \mathrm{z} 141.2(\mathrm{CE}=29 \mathrm{eV})$ for D3-caffeine; $\mathrm{m} / \mathrm{z} 168.2 \rightarrow \mathrm{m} / \mathrm{z} 136.1(\mathrm{CE}=23 \mathrm{eV})$ for adenosine; $\mathrm{m} / \mathrm{z}$ $173.2 \rightarrow \mathrm{m} / \mathrm{z} 136.1$ for C5-adenosine; $\mathrm{m} / \mathrm{z} 347.2 \rightarrow \mathrm{m} / \mathrm{z} 171.1(\mathrm{CE}=38$ $\mathrm{eV}$ ) for 5 -HT; $\mathrm{m} / \mathrm{z} 351.2 \rightarrow \mathrm{m} / \mathrm{z} 171.1(\mathrm{CE}=38 \mathrm{eV})$ for D4-serotonin; $\mathrm{m} / \mathrm{z} 192.1 \rightarrow \mathrm{m} / \mathrm{z} 118.1(\mathrm{CE}=28.6 \mathrm{eV}), \mathrm{m} / \mathrm{z} 91.2(\mathrm{CE}=34.8 \mathrm{eV})$, and $\mathrm{m} / \mathrm{z} 146.0(\mathrm{CE}=14.5 \mathrm{eV})$ for 5 -HIAA; and $\mathrm{m} / \mathrm{z} 197.1 \rightarrow \mathrm{m} / \mathrm{z} 122.1(\mathrm{CE}=$ $29.1 \mathrm{eV}), \mathrm{m} / \mathrm{z} 150.0(\mathrm{CE}=15.6 \mathrm{eV})$, and $\mathrm{m} / \mathrm{z} 151.0(\mathrm{CE}=15.9 \mathrm{eV})$ for D5-5-HIAA. Identification was based on precursor ions, daughter ions and retention times. Quantification was performed using the ratio of daughter ions response areas of the internal standards. Data were normalized to milliliters of plasma or to grams of proteins.

\section{Statistical analysis}

Data are presented as the mean \pm SEM. Statistical analysis was performed by SigmaPlot (version 12, SPSS). Significance was defined at $p<0.05$.

Two-way ANOVA was performed to assess the effect of treatment (SD vs CTR; CAF vs VEH), lighting condition (Dark vs Light pulse) and the interaction between these factors. Two-way ANOVA with repeated measures (for time spent in sleep and wake) was performed to assess the effect of treatment (SD vs CTR; CAF vs VEH), time (CTs), and the interaction between these factors. When appropriate, post hoc analysis was performed using Fisher's least significant difference method. One-way repeated-measure ANOVA was performed to compare total sleep loss during treatments. To compare the 5-HT, 5-HIAA, adenosine, and caffeine contents in SCN, midbrain, and plasma, and the percentage of c-Fos-immunoreactive cells that express calbindin in the SCN after sleep deprivation versus control procedure or caffeine treatment versus vehicle injection, unpaired Student's $t$ tests were used.

\section{Results}

\section{Characterization of sleep deprivation and caffeine-induced arousal by EEG and EMG}

We characterized the sleep loss due to sleep deprivation and caffeine treatments by calculating the time spent per hour in wake and sleep. Both in early and late subjective night, the sleep deprivation protocol enhanced the wake duration and decreased time spent in sleep (Fig. 1). In late night deprivation, but not in early night deprivation, ANOVA revealed that time spent in wake and sleep was affected by the treatment (early night: $F_{(1,110)}=0.16$; $p=0.69$; late-night: $\left.F_{(1,88)}=8.3 ; p=0.02\right)$. Both in early and late night, the time spent in wake and sleep was affected by time (early night: $F_{(11,110)}=8.5 ; p<0.001$; late-night: $F_{(11,88)}=6.3 ; p<$ 0.001 ) and interaction (early night: $F_{(11,110)}=2.8 ; p=0.003$; late-night: $\left.F_{(11,88)}=3.1 ; p=0.001\right)$. In early night, post hoc analysis revealed that the time spent in wake was higher and sleep was lower during the last $2 \mathrm{~h}$ of sleep deprivation $(p<0.05)$ in the sleep-deprived group, and this effect was near to be significant at CT14 ( $p=0.053$; Fig. $1 A, B)$. The time spent in wake was lower and sleep was higher in sleep-deprived animals to the end of the night, from CT21 to CT23 ( $p<0.05)$. In late night, post hoc analysis revealed that time spent in wake was higher and sleep was lower in the sleep-deprived group during the $4 \mathrm{~h}$ period of sleep deprivation $(p<0.001$; Fig. $1 C, D)$. Moreover, total amount of sleep during the experimental night was reduced by sleep deprivation when it occurred in late night $\left(F_{(1,4)}=14 ; p=0.02\right)$, while it was compensated by sleep rebound when animals were sleep deprived in early night $\left(F_{(1,5)}=0.2 ; p=0.6\right)$.

Caffeine treatment in both early and midnight enhanced the time spent in the waking state and reduced the duration of sleep (Fig. 2). In early night treatment, ANOVA revealed that the time spent in wake and sleep was not affected by the treat- 

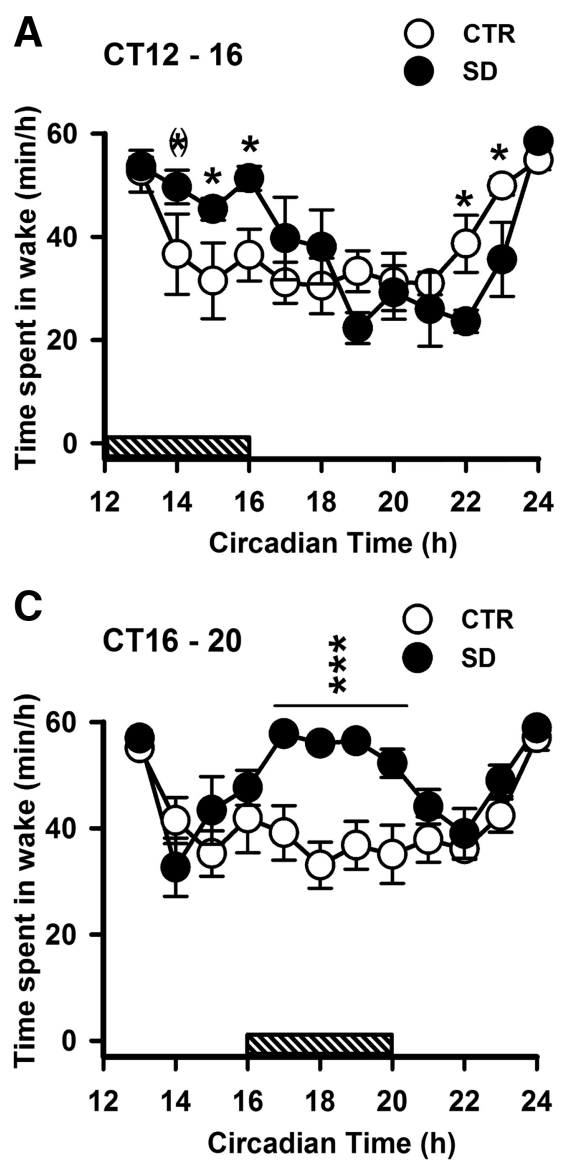

B

CT12 - $16 \quad \bigcirc \quad$ STR
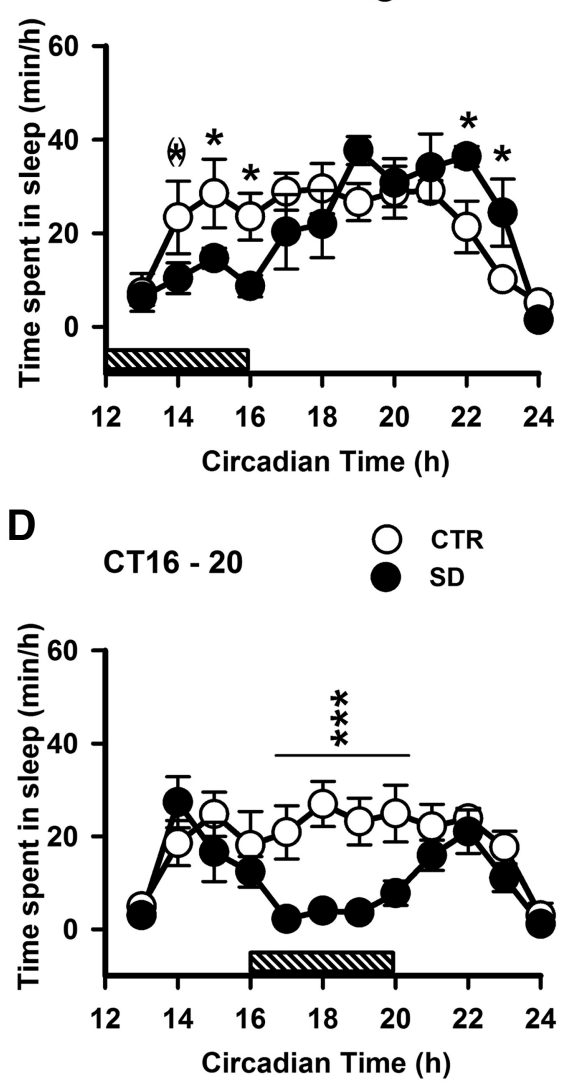

Figure 1. Time course of sleep and waking under DD condition and sleep deprivation experiments. $\boldsymbol{A}-\boldsymbol{D}$, Time course of wakefulness $(\boldsymbol{A}, \boldsymbol{C})$ and sleep $(\boldsymbol{B}, \boldsymbol{D})$ when sleep deprivation was done in early (top) and late (bottom) night. Data are presented as the mean \pm SEM (early night, $n=6$; late night, $n=5$ ). Asterisks indicate a statistically significant difference ${ }^{* * *} p<0.001$, ${ }^{*} p<0.05$ ) between the SD and CTR groups. $\left.{ }^{*}\right)$ A difference close to significance threshold $(p=0.053)$ between the two groups. Horizontal gray bars above $x$-axis represent the timeline of sleep deprivation.

ment $\left(F_{(1,66)}=4.7 ; p=0.07\right)$ but was affected by time $\left(F_{(11,66)}=10.5 ; p<0.001\right)$ and interaction $\left(F_{(11,66)}=1.9 ; p=\right.$ $0.05)$. Post hoc analysis showed that the time spent in wake was higher and the time spent in sleep was lower in the caffeinetreated group for $5 \mathrm{~h}(p<0.05$; Fig. $2 A, B)$. Similarly, in midnight treatment, the time spent in wake and sleep was not affected by the treatment $\left(F_{(1,66)}=4.4 ; p=0.08\right)$ but was affected by time $\left(F_{(11,66)}=9.03 ; p<0.001\right)$ and interaction $\left(F_{(11,66)}=1.97 ; p=0.04\right)$. Post hoc analysis showed that the time spent in wake was higher and sleep was lower in the caffeine-treated group for $2 \mathrm{~h}(p<0.05$; Fig. $2 C, D)$. Furthermore, total amount of sleep during the experimental night was reduced by caffeine treatment when applied in early night $\left(F_{(1,3)}=12.8 ; p=0.03\right)$, while it was unchanged after caffeine injection at midnight $\left(F_{(1,3)}=5.39 ; p=0.1\right)$.

Only early night sleep deprivation induces phase-delay shifts while sleep deprivation in both early and late night potentiates light-induced phase shifts

To evaluate the possible phase shifts of the locomotor activity rhythm in sleep-deprived animals, the offsets of the diurnal pattern of locomotor activity were analyzed by two-way ANOVA using the factors treatment (SD or CTR) and lighting condition (Dark or Light pulse).

Regarding the sleep deprivation in early night (CT12 to C16), the behavioral shifts were significantly modified by treatment vances compared with light-exposed undisturbed controls $(p=0.05)$. Furthermore, phase advances in the SD plus Light group were significantly higher compared with the SD plus Dark group $(p=0.006)$.

The free-running period of wheel-running activity rhythm was close to $24 \mathrm{~h}$ and was not influenced by sleep deprivation at night (data not shown).

Daytime caffeine treatment does not induce a phase shift or influence light-induced phase shifts

Caffeine treatment $(30 \mathrm{mg} / \mathrm{kg})$ in the early subjective morning (CT0) and mid-subjective day (CT6) did not induce significant phase shifts in the locomotor activity rhythm or significantly change light-induced phase shifts. ANOVA revealed the significant effect of lighting condition $\left(F_{(1,20)}=7.4 ; p=0.01\right)$ in early subjective morning (Fig. 4A-D,I). Post hoc analysis indicated that phase shifts were significantly larger after VEH plus Light than after VEH plus Dark $(p=0.03)$. After caffeine treatment during the mid-subjective day, we did not observe any significant effect of treatment $\left(F_{(1,20)}=0.47\right.$; $p=0.49)$, lighting condition $\left(F_{(1,20)}=0.39 ; p=0.53\right)$, or interaction $\left(F_{(1,20)}=0.1 ; p=0.74\right.$; Fig. $\left.4 E-H, J\right)$.

The free-running period of wheel-running activity rhythm was close to $24 \mathrm{~h}$ and was not influenced by CAF or VEH during daytime (data not shown). 
Caffeine treatment in early and late night potentiates light-induced phase shifts

Caffeine treatment in early subjective night (CT14) and mid-subjective night (CT18) potentiated light-induced phase delays and advances, respectively. ANOVA revealed that both caffeine treatment in the early night-induced (CAF or VEH; $F_{(1,20)}=6.4$; $p=0.02)$ and light-induced $\left(F_{(1,20)}=40\right.$; $p<0.001)$ significant phase delays. The nonsignificant interaction $\left(F_{(1,20)}=1.18\right.$; $p=0.29$ ) indicates that the effect of caffeine was independent of the lighting condition (Fig. 5A-D, I). CAF plus light treatment induced phase delays that were significantly greater than those after VEH plus Light $(p=$ $0.01)$ and CAF plus Dark $(p<0.001)$. Phase delays induced by VEH plus Light treatment were significantly higher compared with VEH plus Dark treatment $(p=0.001)$.

Similar to early night, caffeine (CAF or VEH; $\left.F_{(1,20)}=5.4 ; p=0.03\right)$ and light $\left(F_{(1,20)}=40.9 ; p<0.001\right)$ treatment during late night-induced significant phase advance. The nonsignificant interaction $\left(F_{(1,20)}=1.18 ; p=0.29\right)$ indicates that also during late night the effect of caffeine treatment was independent of the lighting condition (Fig. 5E-H,J). CAF plus Light treatment-induced phase advances were significantly greater than those after $\mathrm{VEH}$ plus Light $(p=0.02)$ and CAF plus Dark $(p<0.001)$ treatment. Phase advances induced by VEH plus Light treatment were significantly higher compared with $\mathrm{VEH}$ plus Dark treatment ( $p=0.001)$.

The free-running period of wheel-running activity rhythm was close to $24 \mathrm{~h}$ and not influenced by CAF or VEH during the night time (data not shown).

Early night sleep deprivation potentiates light-induced c-Fos expression in ventral SCN

Light pulses at CT16 and CT20 increased c-Fos expression in the dorsal as well as the ventral SCN (Fig. 6A-D; Light effect at CT16: dorsal SCN, $F_{(1,16)}=346.4, p<0.001$; ventral SCN, $F_{(1,16)}=$ $126.2, p<0.001$; Light effect at CT20: dorsal SCN, $F_{(1,16)}=94.8$, $p<0.001$; ventral SCN, $\left.F_{(1,16)}=165.6, p<0.001\right)$. ANOVA detected the effect of early night sleep deprivation on c-Fos expression in ventral SCN $\left(F_{(1,16)}=6.38, p=0.02\right)$ and a significant interaction between sleep deprivation and light in dorsal SCN $\left(F_{(1,16)}=4.04, p=0.04\right)$. Post hoc analysis indicated that at CT16 the light-induced c-Fos expression in the ventral SCN was significantly greater in sleep-deprived animals than in non-sleepdeprived controls $(p=0.007)$.

Caffeine treatment induces c-Fos expression in the dorsal SCN and potentiates light-induced c-Fos expression in ventral SCN

We also examined the effect of caffeine-induced arousal on c-Fos expression in the master clock. During the early subjective night, c-Fos expression in the dorsal SCN was altered only by lighting condition $\left(F_{(1,20)}=30.9 ; p<0.001\right)$. Post hoc
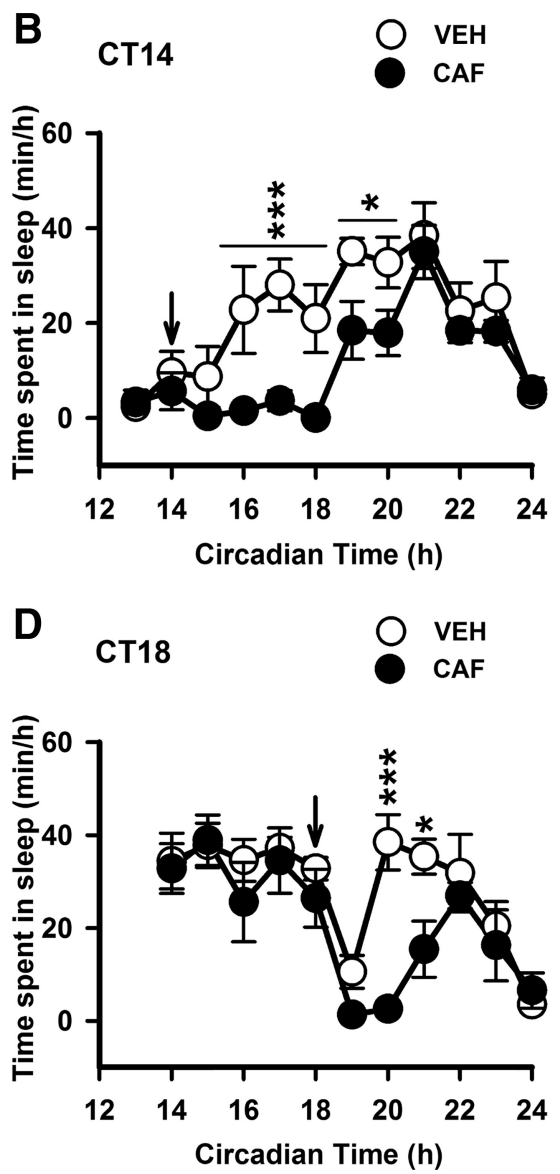

Figure 2. Time course of sleep and waking under DD condition and following vehicle and caffeine administration. $A-D$, Time course of wakefulness $(\boldsymbol{A}, \boldsymbol{C})$ and sleep $(\boldsymbol{B}, \boldsymbol{D})$ after intraperitoneal administration of VEH or CAF in early (top) and midnight (bottom). Data are presented as mean $\pm \operatorname{SEM}(n=4)$. Asterisks indicate a statistically significant difference $\left({ }^{* * *} p<0.001,{ }^{*} p<\right.$ $0.05)$ between caffeine and vehicle injected groups. Arrow indicates the time of injection.

analysis indicated that the number of c-Fos-positive nuclei in VEH plus Light-treated group was significantly higher compared with Dark controls $(p=0.004)$. In the ventral SCN, c-Fos expression was altered by both treatment (CAF or VEH; $\left.F_{(1,20)}=9.6 ; p=0.005\right)$ and lighting condition $\left(F_{(1,20)}=\right.$ $189.4 ; p<0.001)$. Post hoc analysis indicated a significant increase in the number of c-Fos-positive nuclei in the ventral SCN of the CAF plus Light group compared with the VEH plus Light $(p=0.003)$ and CAF plus Dark $(p<0.001)$ groups. The number of c-Fos-positive nuclei in the VEH plus Light treatment group was also significantly higher than that in the Dark controls $(p<0.001$; Fig. $7 A, C)$.

During mid-subjective night, c-Fos expression in the dorsal SCN was altered by treatment $\left(F_{(1,20)}=6.5 ; p=0.01\right)$ and lighting condition $\left(F_{(1,20)}=96.6 ; p<0.001\right)$. Post hoc analysis indicated a significant increase in the number of c-Fospositive nuclei in the dorsal SCN of the CAF plus Dark group compared with the VEH plus Dark group $(p=0.02)$. The number of c-Fos-positive nuclei in the VEH plus Light treatment group was also significantly higher compared with Dark controls $(p<0.001)$. Moreover, in the ventral SCN, c-Fos expression was also altered by treatment $\left(F_{(1,20)}=6.8 ; p=\right.$ $0.008)$ and lighting condition $\left(F_{(1,20)}=280.2 ; p<0.001\right)$. A significant increase in the number of Fos-positive nuclei in the ventral SCN of the CAF plus Light group was detected compared with the VEH plus Light $(p=0.01)$ and CAF plus Dark 

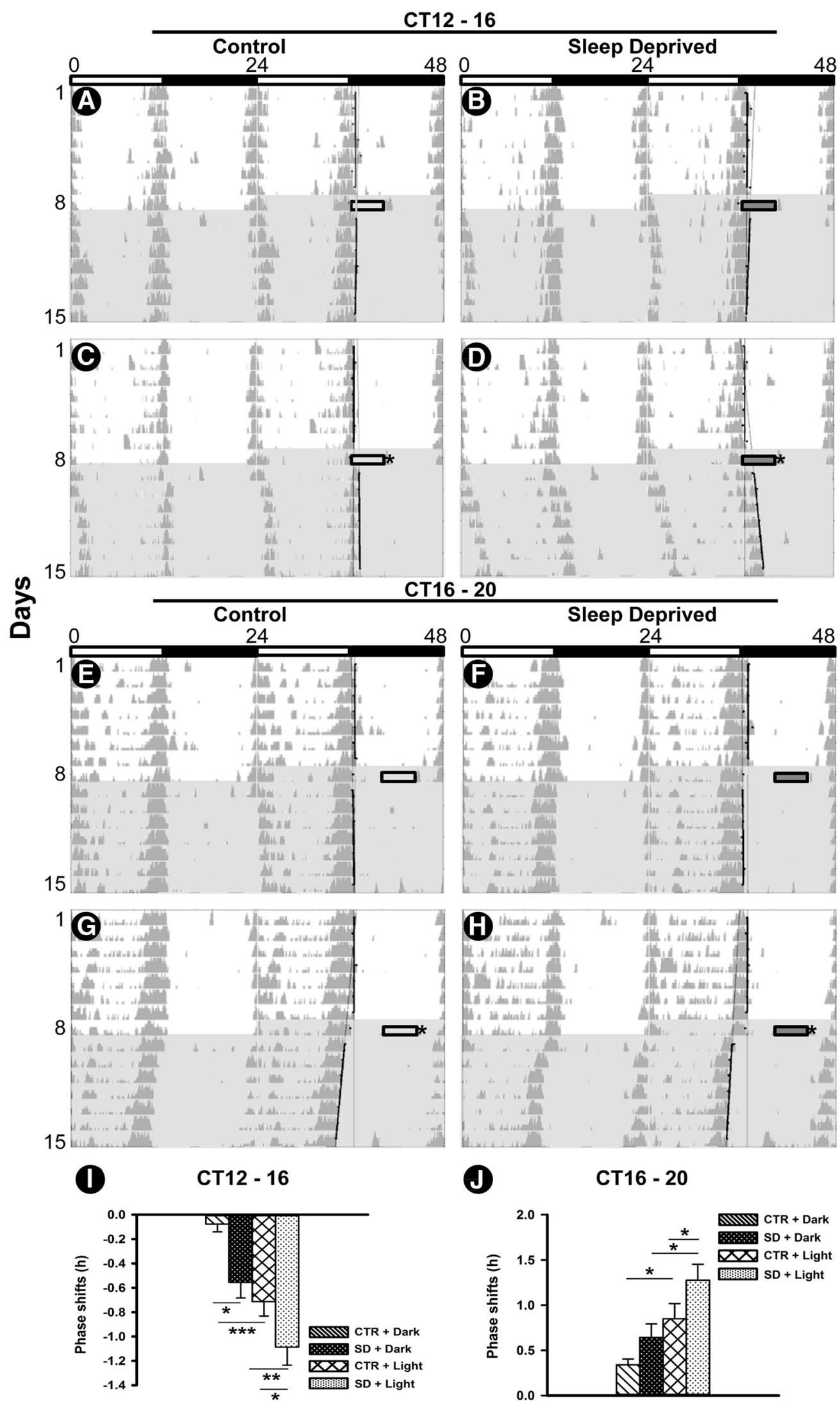

Figure 3. Representative double-plotted actograms of wheel-running activity during 1 week under a light/dark cycle and 1 week in DD, displaying phase shifts to sleep deprivation, light pulse, and the combined effects of sleep deprivation and light pulse. $\boldsymbol{A}-\boldsymbol{H}, 0$ n the first day of $D$, in early night $(\boldsymbol{A}-\boldsymbol{D})$ and late night $(\boldsymbol{E}-\boldsymbol{H})$ animals were sleep deprived (right) or left undisturbed as control (left), in darkness (top) or followed by light pulse at CT16 and (T20, respectively (bottom). $I, J$, Mean phase delays (negative value) and phase advances (positive) to sleep deprivation, light pulse, and the combination of both in early night $(I)$ and late night $(J)$. Data are presented as the mean $\pm \operatorname{SEM}\left(n=6\right.$ per group). Asterisks indicate a statistically significant difference $\left({ }^{* * *} p<0.001,{ }^{* *} p<0.01,{ }^{*} p<0.05\right)$. Shaded area, DD, rectangular gray and dark gray bars (time line of shifting animal out of home cage for keeping it undisturbed or sleep deprived, respectively); Stars, light pulse (200 lux for $30 \mathrm{~min}$ ). 

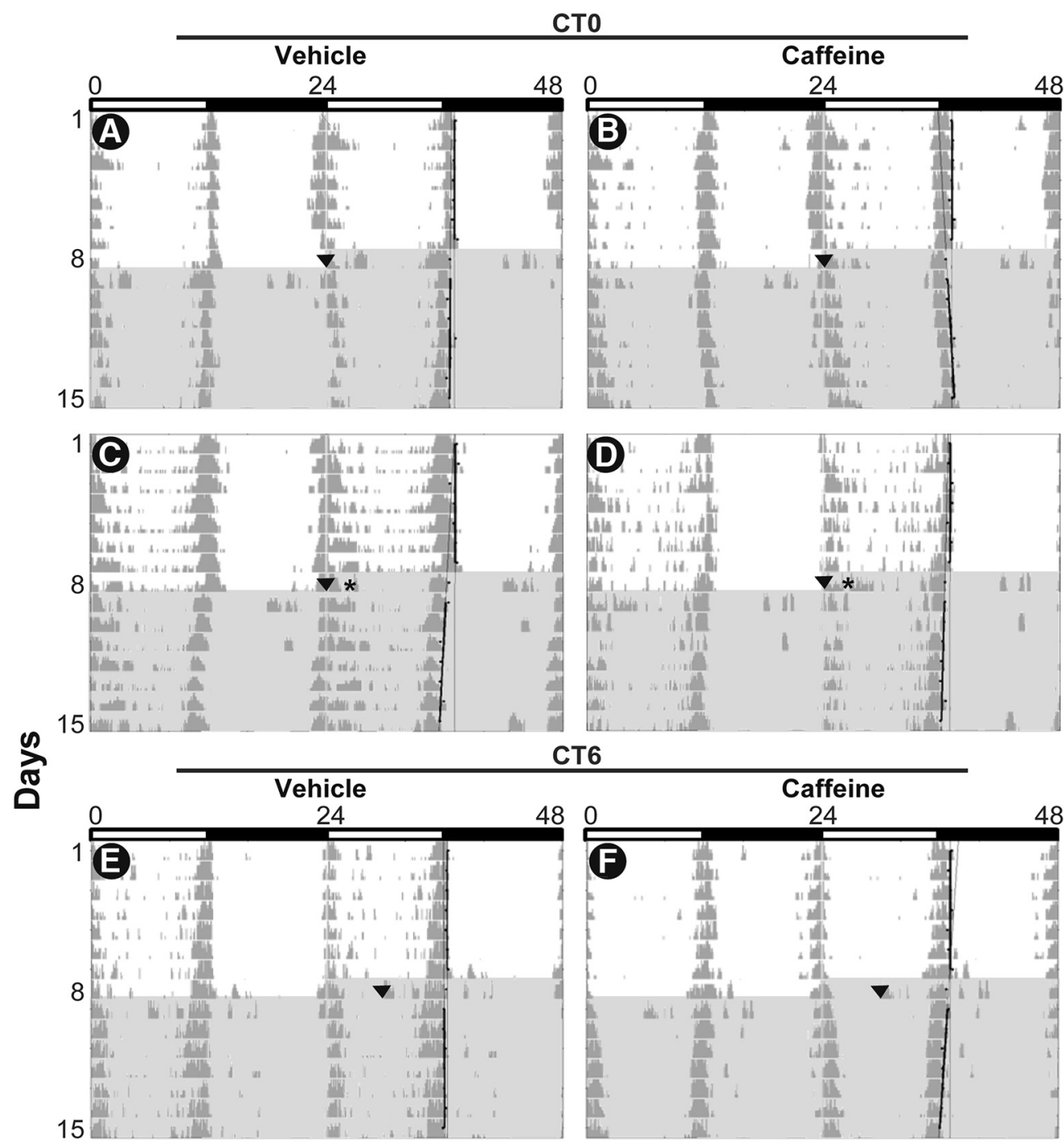

CT6
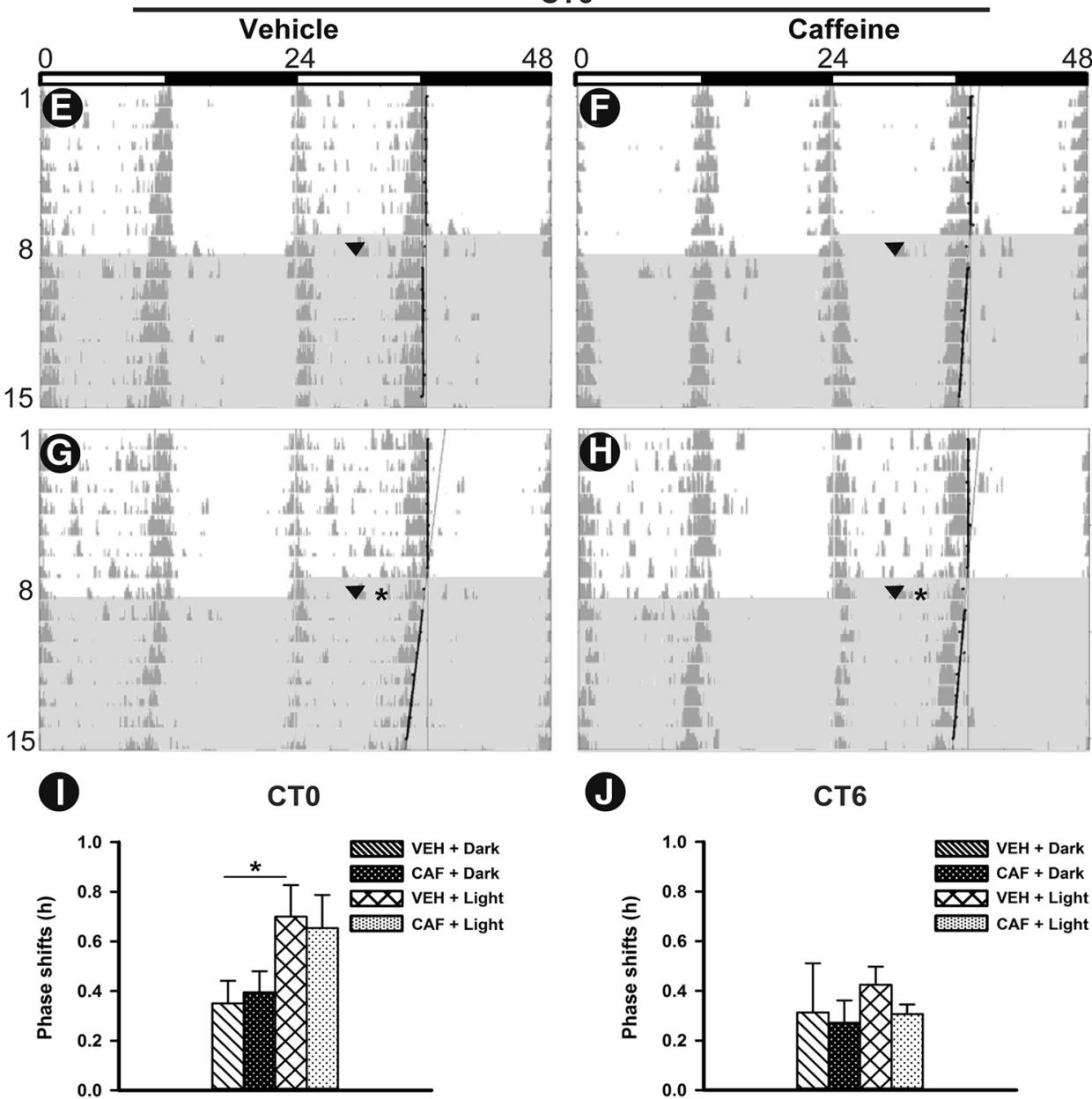

Figure 4. Representative double-plotted actograms of wheel-running activity during 1 week under a light/dark cycle and 1 week in DD, displaying phase shifts to caffeine treatment, light pulse,

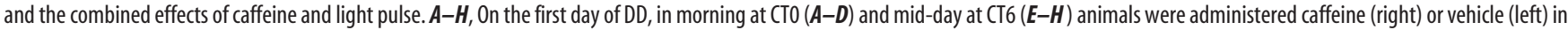
dark (top) or followed by light pulse at CT2 or CT8, respectively (bottom). $I, J$, Mean phase advances (positive) to caffeine treatment, light pulses and combination of both in the morning $(I)$ and mid-day $(J)$. Data are presented as the mean \pm SEM $(n=6$ per group). An asterisk indicates a statistically significant difference $(p<0.05)$. Shaded area, DD; arrows, time of injection; stars, light pulse (200 lux for $30 \mathrm{~min}$ ). 

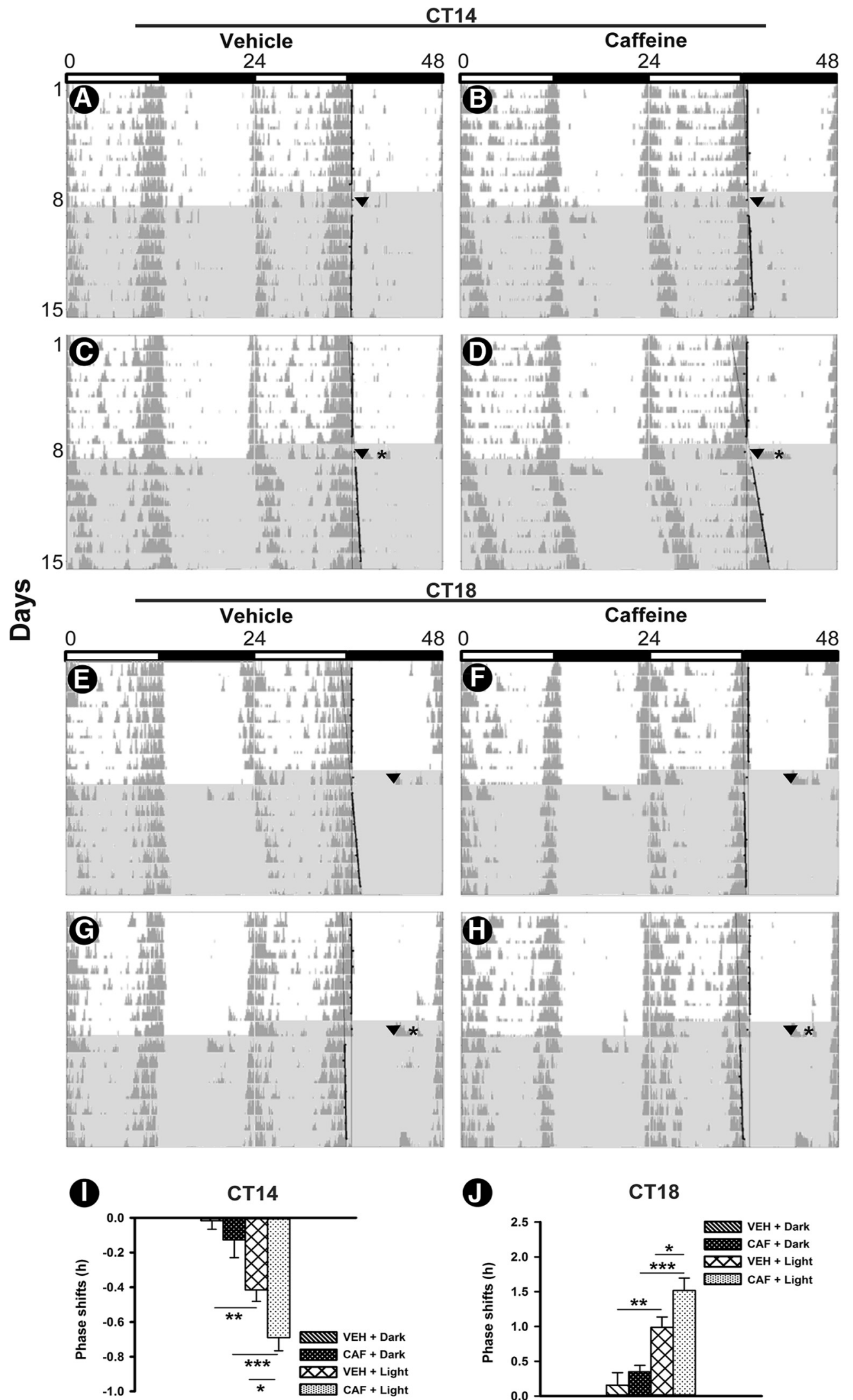

J

CT18

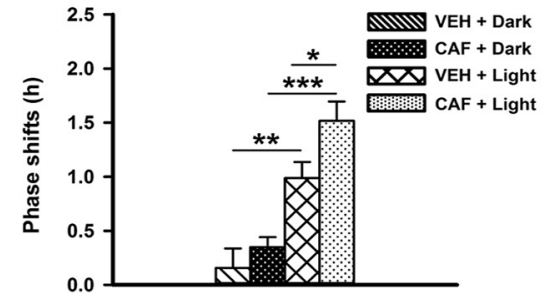

Figure 5. Representative double-plotted actograms of wheel-running activity during 1 week under a light/dark cycle and 1 week in DD, displaying phase shifts to caffeine treatment, light pulse, and the combined effects of caffeine and light pulse. $\boldsymbol{A}-\boldsymbol{H}, 0$ n the first day of DD, in early night at CT14 (A-D) and mid-night CT18 (E-H) animals were administered caffeine (right) or vehicle (left) in dark (top) or followed by light pulse at CT16 or CT20, respectively (bottom). $I, J$, Mean phase delays (negative value) and phase advances (positive) to caffeine treatment, light pulse, and the combination of both in early night $(\boldsymbol{I})$ and mid-night $(\boldsymbol{J})$ periods. Data are presented as the mean $\pm \operatorname{SEM}(n=6$ per group). Asterisks indicate a statistically significant difference $(* * * p<0.001$, $\left.{ }^{* *} p<0.01,{ }^{*} p<0.05\right)$. Shaded area, DD; arrows, time of injection; stars, light pulse (200 lux for $30 \mathrm{~min}$ ). 
CT12 - 16

A

\section{Control}
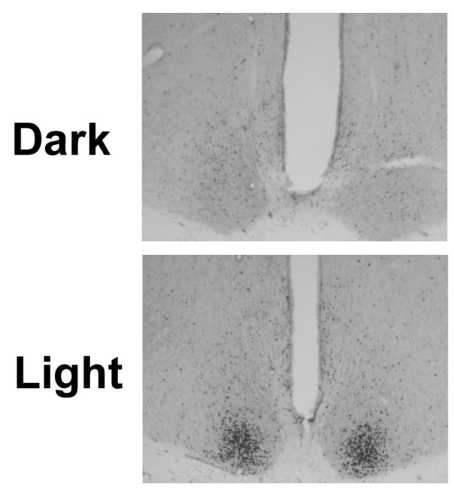

C

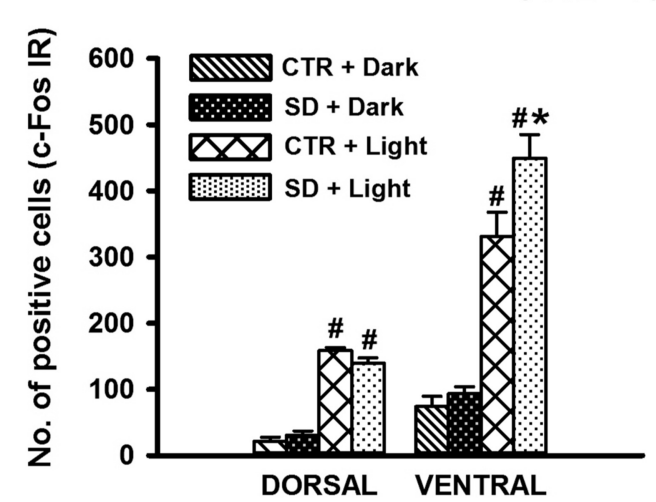

CT16 - 20

B

Control
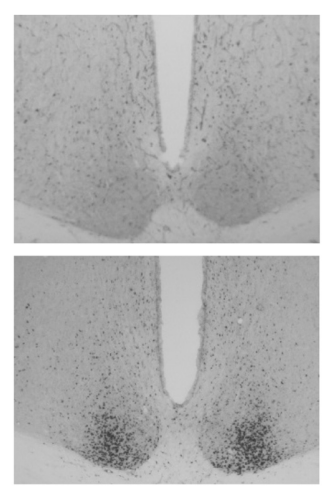

D

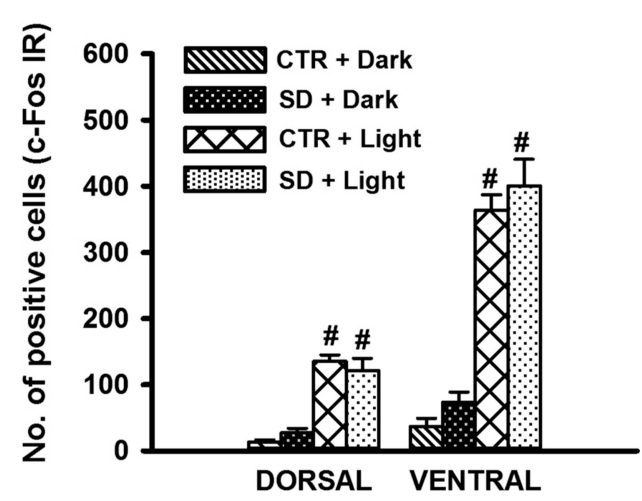

Figure 6. C-Fos expression in the SCN after sleep deprivation. $A, B$, Representative photomicrographs of c-Fos in the SCN of early and late-night sleep-deprived (right) and control (left) Arvicanthis in darkness (top) or with exposure of light pulse for 30 min at the end of the sleep deprivation (bottom). C, D, c-Fos mean responses of dorsal and ventral parts of the SCN of early-night and late-night sleep-deprived and control Arvicanthis in darkness or with exposure of light pulse at the end of the sleep deprivation. Data are presented as the mean \pm SEM $\left(n=6\right.$ per group). ${ }^{*} p<0.05$ between sleep-deprived and control groups; $\# p<0.001$ between light and dark conditions.

$(p<0.001)$ groups. The number of c-Fos-positive nuclei in the VEH plus Light group was also significantly higher compared with Dark controls $(p<0.001$; Fig. $7 B, D)$.

\section{Sleep deprivation and caffeine treatment alone or with light pulses activate calbindin-containing cells in the SCN}

To phenotype the activated cells in the SCN by arousal and/or light pulse, we performed double immunolabeling for calbindin and c-Fos. In the dorsoventral SCN, we calculated the percentage of calbindin cells that were c-Fos IR. Both during early night and late night sleep deprivation, ANOVA revealed that the percentage of calbindin cells coexpressing c-Fos IR were modified by treatment (early night: $F_{(1,16)}=37.3 ; p<0.001$; late night: $F_{(1,16)}=$ $153.5 ; p<0.001)$ and lighting condition (early night: $F_{(1,16)}=$ 46.6; $p<0.001$; late night: $F_{(1,16)}=420.8$; $p<0.001$; Fig. $8 A-C$ ). Post hoc analysis showed that both in early and late night, the percentages of calbindin cells showing c-Fos immunoreactivity were significantly higher in the SD plus Dark group compared with the CTR plus Dark group $(p<0.001)$. Moreover, these percentages were also higher in the SD plus Light group compared with the CTR plus Light group (early night, $p=0.007$; late night, $p=0.002$ ) and the SD plus Dark group (early night, $p=$ 0.002 ; late night, $p<0.001$ ). In both conditions, CTR plus Light group showed a higher percentage of expression than CTR plus
Dark $(p<0.001)$. We also analyzed the percentage of c-Fosimmunoreactive cells that express calbindin in dark conditions. Sleep deprivation significantly enhances calbindin expression in c-Fos-positive cells in early night $(22.5 \pm 3.0$ vs $8.8 \pm 2.2 \%$, respectively, in the SD plus Dark and CTR plus Dark groups; $t_{(8)}=3.7 ; p_{\text {two-tailed }}=0.006$ ), while only a trend for an increase is observed in late night $(21.1 \pm 5.9$ vs $7.1 \pm 3.1 \%$, respectively, in the SD plus Dark and CTR plus Dark groups; $t_{(8)}=$ $2.1 ; p_{\text {two-tailed }}=0.06$ ).

Similar to sleep deprivation, in both early night and midnight, ANOVA revealed that the percentages of the calbindin cells showing c-Fos IR were different after caffeine treatment (early night: $F_{(1,20)}=27.3 ; p<0.001$; mid-night: $F_{(1,20)}=134.4 ; p<$ 0.001 ) and light exposure (early night: $F_{(1,20)}=12.18 ; p=0.002$; mid-night: $F_{(1,20)}=45.8 ; p<0.001$; Fig. $\left.9 A-C\right)$. Post hoc analysis showed that both in early and mid-night the percentages of calbindin cells coexpressing c-Fos were significantly higher in the CAF plus Dark group compared with the VEH plus Dark group $(p<$ 0.001). Moreover, these percentages were also higher in the CAF plus Light group compared with the VEH plus Light group (early night, $p=0.007$; mid-night, $p<0.001)$ and the CAF plus Dark group (early night, $p=0.005$; mid-night, $p<0.001$ ). In both conditions, the VEH plus Light group showed a higher expression percentage than that of the VEH plus Dark group (early night, $p=0.005$; mid 

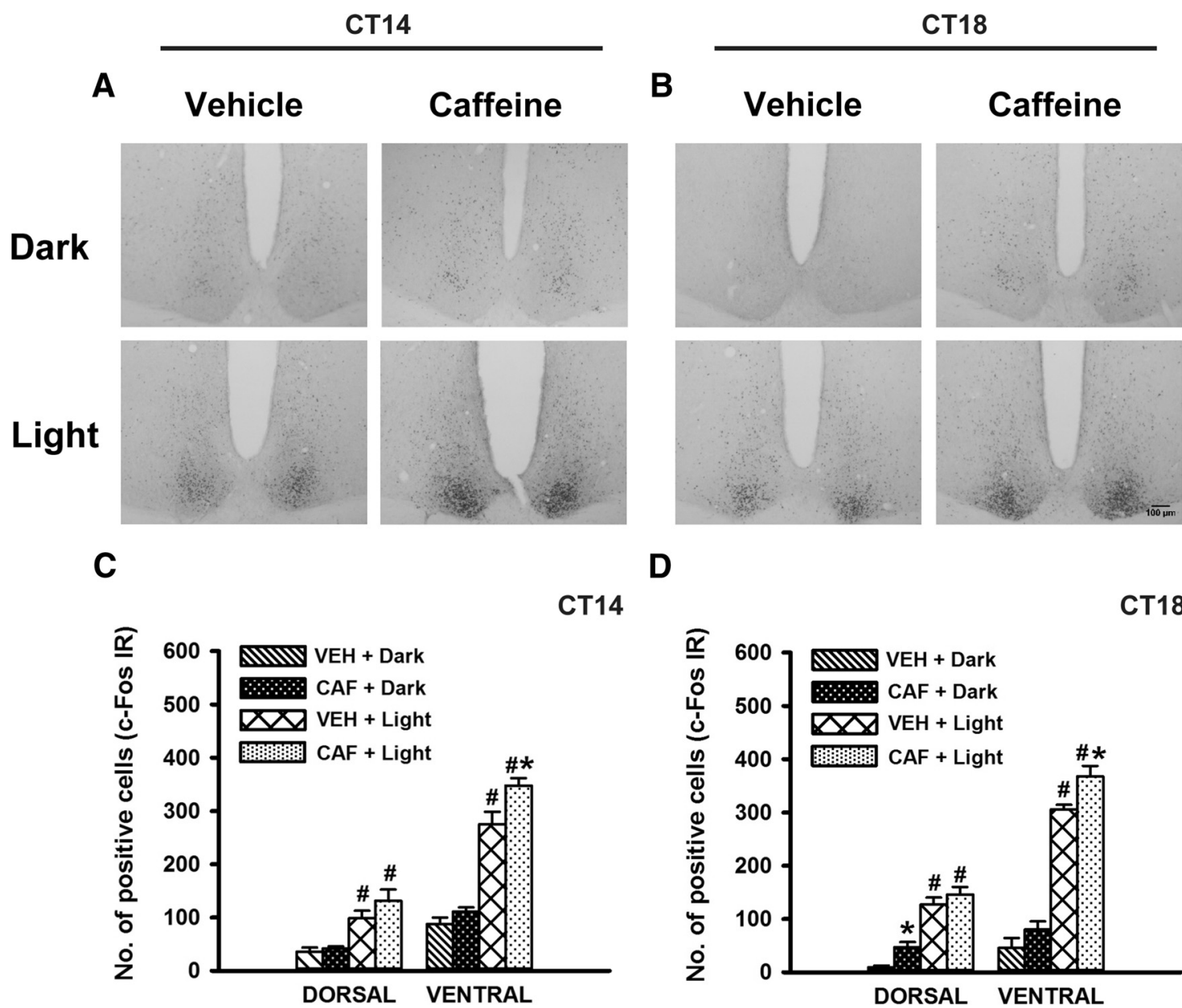

D

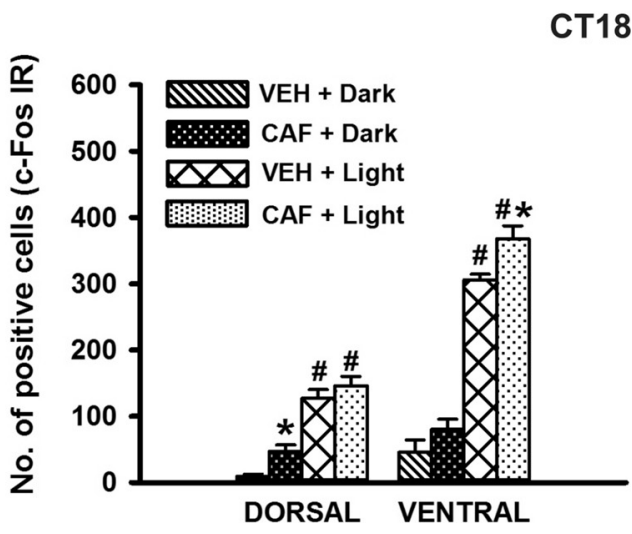

Figure 7. C-Fos expression in the $\mathrm{SCN}$ after caffeine treatment. $A, B$, Representative photomicrographs of c-Fos in the $S C N$ of early and midnight caffeine (right) or vehicle-treated (left) Arvicanthis in darkness (top) or with the exposure of light pulse for $30 \mathrm{~min}$ at $\mathrm{CT} 16$ and $\mathrm{CT20}$, respectively (bottom). C, D, C-Fos mean responses of dorsal and ventral parts of the $S C N$ of early night and mid-night vehicle- and caffeine-treated Arvicanthis in darkness or with exposure of light pulse at CT16 and CT20, respectively. Data are presented as the mean \pm SEM $\left(n=6\right.$ per group). ${ }^{*} p<0.05$ between caffeine- and vehicle-injected groups; $\# p<0.001$ between light and dark conditions.

night, $p<0.001$ ). Remarkably, the mean effect of caffeine (CAF plus Dark vs VEH plus Dark group) appeared even stronger than that of light (VEH plus Light vs VEH plus Dark group), although this difference (CAF plus Dark vs VEH plus Light group) did not reach significance. Again, we analyzed the percentage of c-Fos-immunoreactive cells that express calbindin in dark conditions. Caffeine treatment significantly enhances calbindin expression in c-Fospositive cells in both early night $(40.1 \pm 3.9 \mathrm{vs} 7.1 \pm 2.3 \%$, respectively, in the CAF plus Dark and VEH plus Dark groups; $t_{(10)}=7.2$; $\left.p_{\text {two-tailed }}<0.001\right)$ and late night $(44.2 \pm 2.4$ vs $4.8 \pm 2.5 \%$, respectively, in CAF plus Dark and VEH plus Dark groups; $t_{(10)}=4.3$; $p_{\text {two-tailed }}=0.001$.

\section{5-HT and 5-HIAA content in the SCN after}

\section{fluoxetine treatment}

In keeping with previous findings in several brain regions of rats treated with a single dose of $10 \mathrm{mg} / \mathrm{kg}$ fluoxetine (Caccia et al., 1993; Bourdeaux et al., 1998), such treatment increased serotonergic activity in the $\mathrm{SCN}$ region of diurnal grass rats, as shown by decreased concentrations of 5-HIAA, the main metabolite of 5-HT, $(-20 \%)$, compared with animals injected with vehicle $(71.3 \pm 4.4$ vs $88.0 \pm$ $5.3 \mathrm{nmol} / \mathrm{g}$ protein, respectively; $\left.t_{(8)}=2.4 ; p_{\text {two-tailed }}=0.04\right)$, without changes of $5-\mathrm{HT}$ content $(9.3 \pm 1.7 \mathrm{vs} 11.1 \pm 1.5 \mathrm{nmol} / \mathrm{g}$ protein, respectively; $\left.t_{(8)}=0.8 ; p_{\text {two-tailed }}=0.1\right)$.
5-HT, 5-HIAA, and adenosine content in the SCN and 5-HT and adenosine content in midbrain after early night sleep deprivation or caffeine treatment

The levels of 5-HT, 5-HIAA, and adenosine in SCN and those of 5-HT and adenosine in midbrain were assessed after sleep deprivation and caffeine treatment during early subjective night (CT14; Table 1). The levels of 5-HT and 5-HIAA in SCN or 5-HT levels in midbrain were not different from those in midbrain after sleep deprivation (Table 1). Caffeine treatment enhanced midbrain levels of 5 -HT significantly $\left(t_{(10)}=3.22, p_{\text {two-tailed }}=0.007\right)$, although SCN levels of 5-HT remained unchanged after caffeine injection (Table 1). The level of adenosine in $\mathrm{SCN}$ and midbrain did not change after sleep deprivation or caffeine treatment (Table 1).

Caffeine content in SCN, midbrain, and plasma $3 \mathrm{~h}$ after caffeine injection in early night

The levels of caffeine in the SCN, midbrain, and plasma were quantified $3 \mathrm{~h}$ after caffeine or vehicle injection in the early night (Table 2). In addition to plasma, caffeine levels in the SCN and midbrain were markedly elevated in caffeine-treated animals (plasma: $t_{(10)}=4.5 ; p_{\text {two-tailed }}<0.001 ; \mathrm{SCN}: t_{(10)}=3.6$; $p_{\text {two-tailed }}=$ 0.004; midbrain: $\left.t_{(10)}=14.8 ; p_{\text {two-tailed }}<0.001\right)$, indicating that caffeine can directly target these brain areas. 
A

\section{Control}

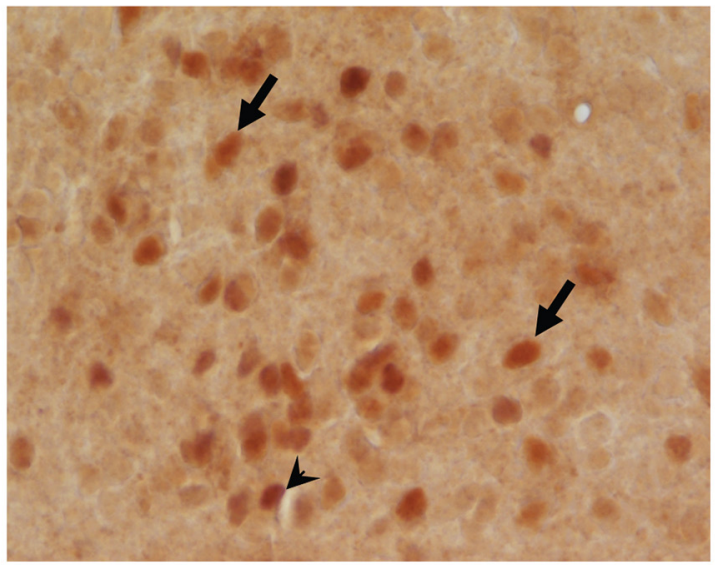

Dark

\section{Light}

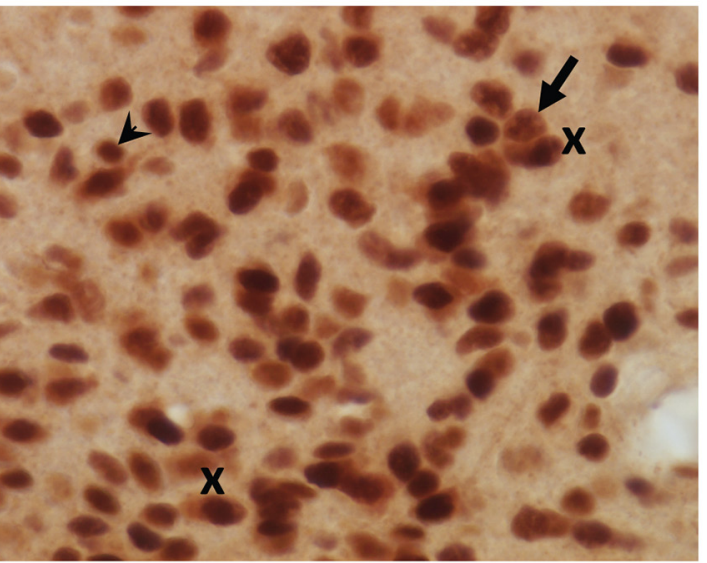

B

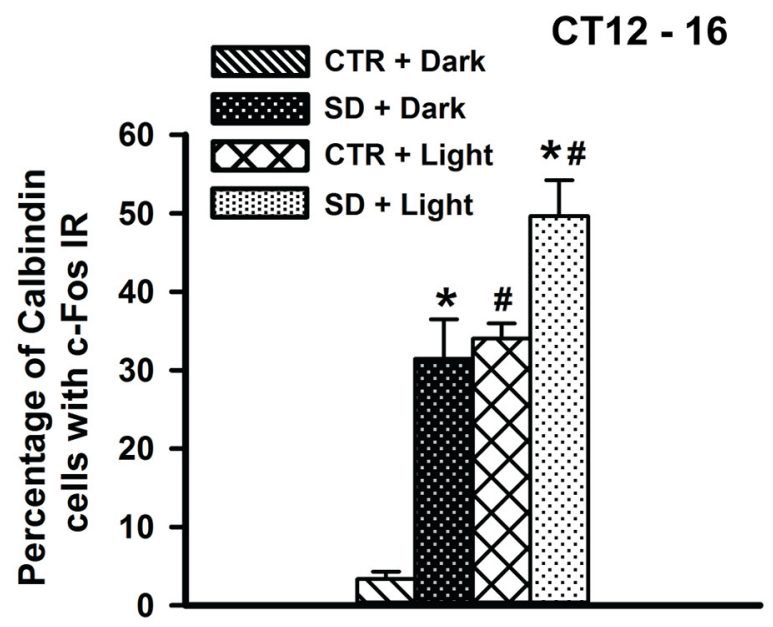

Sleep Deprived
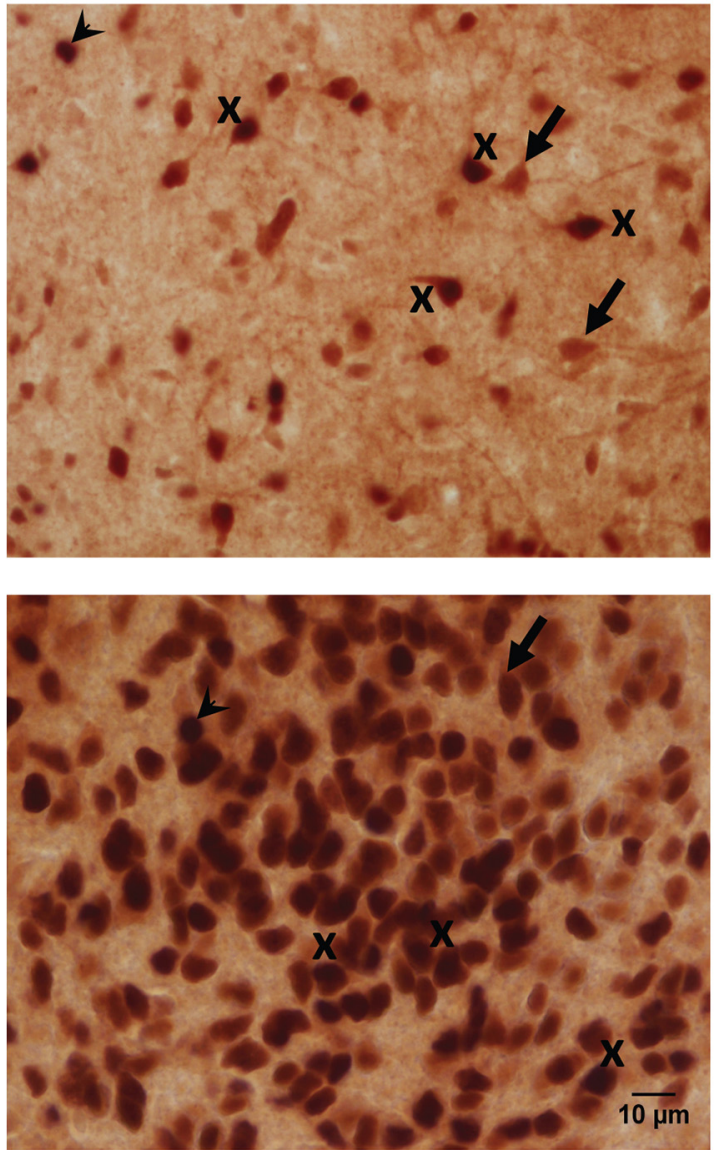

C

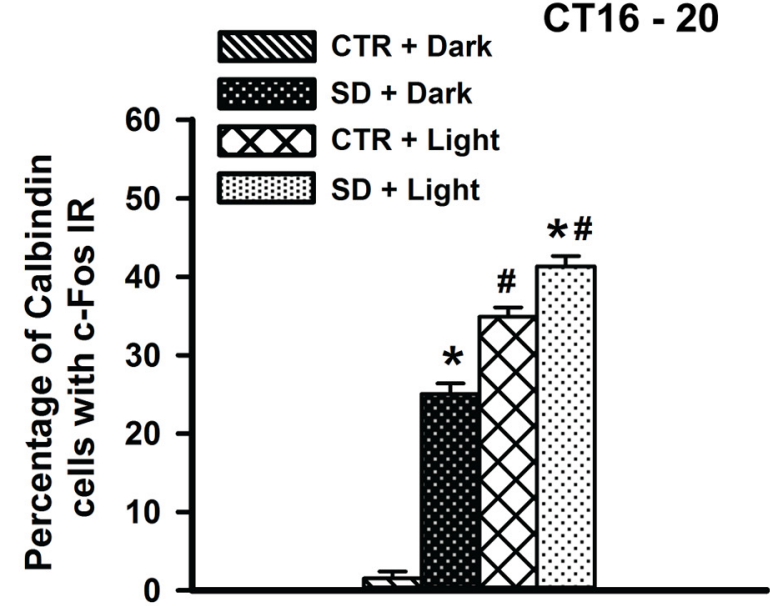

Figure 8. Calbindin expression in c-Fos-positive cells in the SCN after sleep deprivation. A, Representative photomicrographs of the SCN of early night sleep-deprived (right) and control (left) Arvicanthis in darkness (top) or with exposure of light pulse for 30 min at CT16 (bottom), showing c-Fos (dark black nucleus) and calbindin (light brown soma). Arrowheads, Single c-Fos-IR neurons; arrows, single calbindin IR neurons; cross, neurons positive for both c-Fos and calbindin IR. B, C, Mean percentage of calbindin neurons with c-Fos IR in the SCN of $(\boldsymbol{B})$ early night and $(\boldsymbol{C})$ late night sleep-deprived and control Arvicanthis in darkness or with exposure of light pulse at CT16 and CT20, respectively. Data are presented as the mean \pm SEM ( $n=6$ per group). ${ }^{*} p<0.001$ between sleep-deprived and control; \#p $<0.001$ between light and dark conditions. 


\section{CT14}

A

\section{Dark}
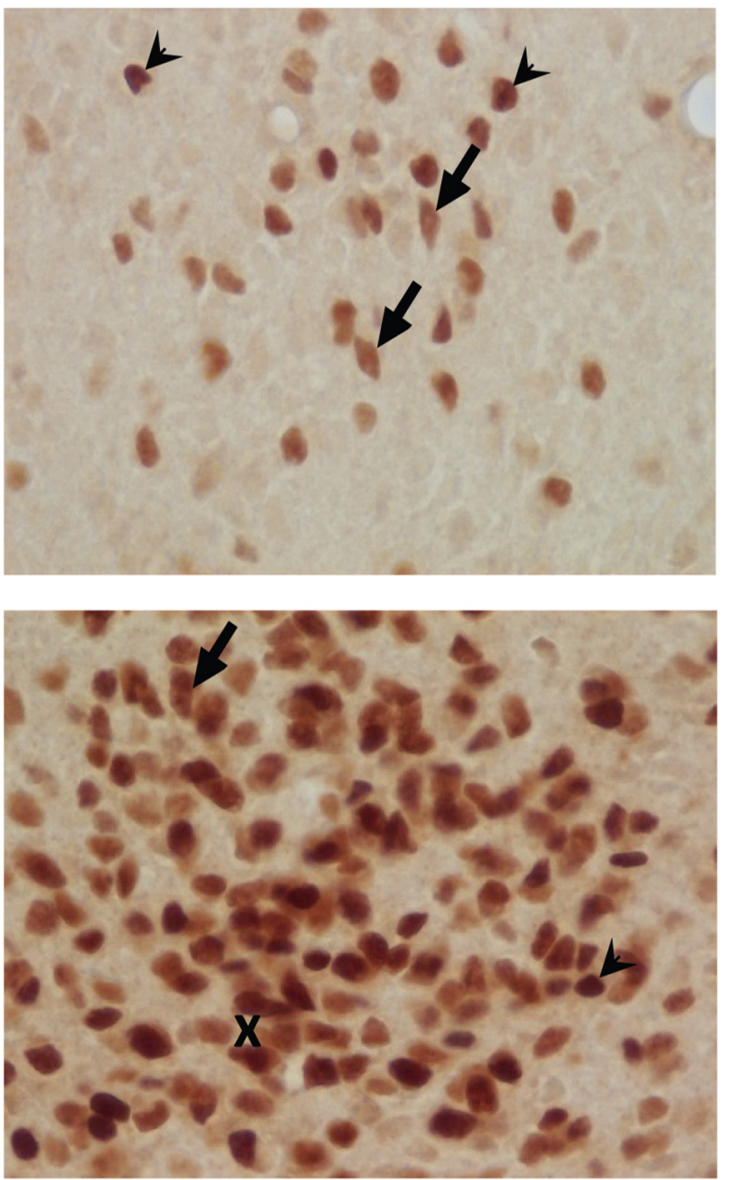

B

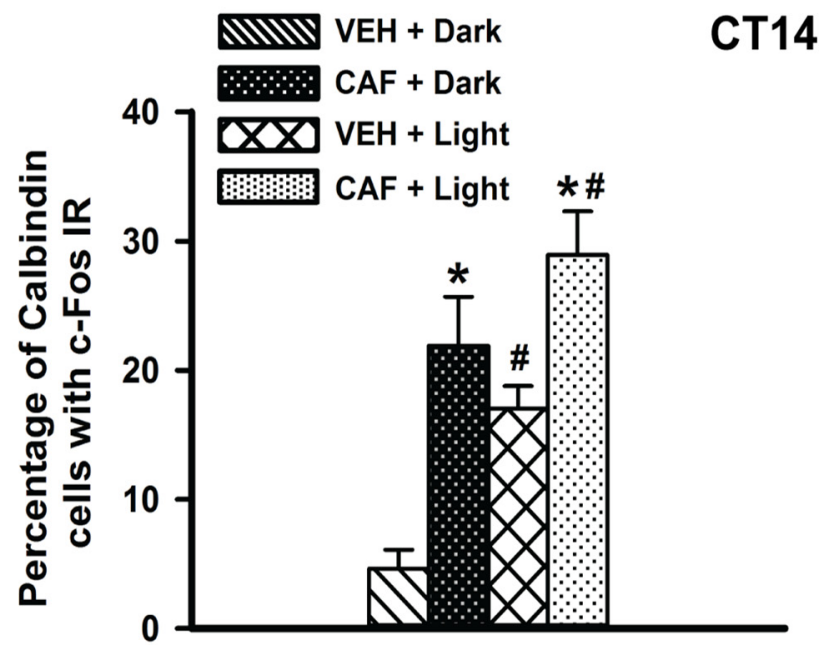

Caffeine
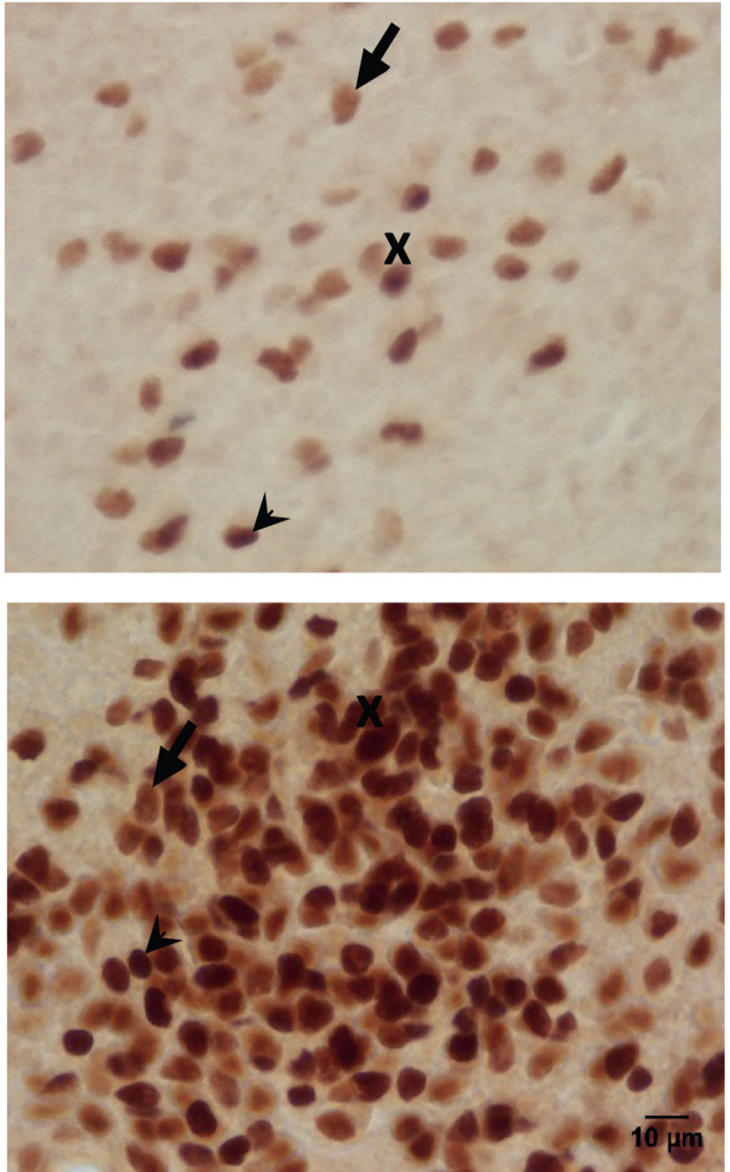

C

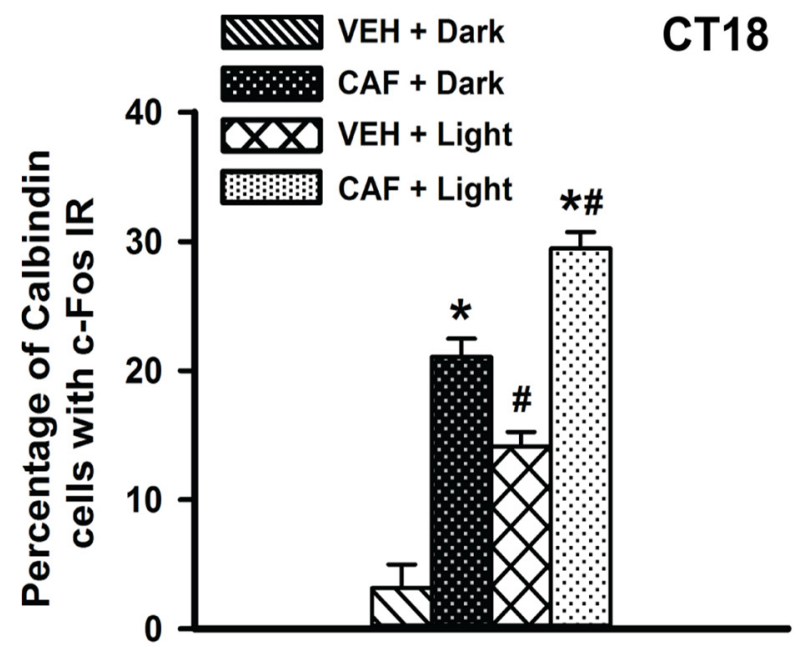

Figure 9. Calbindin expression in c-Fos-positive cells in the SCN after caffeine treatment. $A$, Representative photomicrographs of the SCN of early night caffeine (right) or vehicle-treated (left) Arvicanthis in darkness (top) or with exposure of light pulse for 30 min at CT16 (bottom), showing c-Fos (dark black nucleus) and calbindin (light brown soma). Arrowheads, Single c-Fos-IR neurons; arrows, single calbindin IR neurons; cross, neurons positive for both c-Fos and calbindin IR. B, C, Mean percentage of calbindin neurons with c-Fos IR in the SCN of early night (B) and mid-night caffeine- or vehicle-treated Arvicanthis $(C)$ in darkness or with exposure of light pulse at CT16 and CT20, respectively. Data are presented as the mean \pm SEM $\left(n=6\right.$ per group). ${ }^{*} p<0.001$ between caffeine and vehicle injected group; $\# p<0.001$ between light and dark conditions. 
Table 1.5-HT and/or 5-HIAA and adenosine contents in the SCN and midbrain after sleep deprivation or caffeine treatment in early subjective night

\begin{tabular}{|c|c|c|c|c|}
\hline & CTR & SD & VEH & CAF \\
\hline SCN 5-HT (nmol/g protein) & $40.17 \pm 2.66$ & $40.20 \pm 3.52$ & $37.57 \pm 2.49$ & $44.43 \pm 4.75$ \\
\hline SCN 5-HIAA (nmol/g protein) & $160.09 \pm 10.46$ & $145.18 \pm 19.93$ & $130.22 \pm 19.52$ & $179.88 \pm 29.85$ \\
\hline Midbrain 5-HT (nmol/g protein) & $7.07 \pm 0.69$ & $6.59 \pm 0.38$ & $6.05 \pm 0.64$ & $8.64 \pm 0.59 *$ \\
\hline SCN adenosine ( $\mu \mathrm{mol} / \mathrm{g}$ protein) & $7.69 \pm 1.14$ & $9.71 \pm 1.84$ & $7.18 \pm 1.20$ & $7.3 \pm 1.40$ \\
\hline Midbrain adenosine ( $\mu \mathrm{mol} / \mathrm{g}$ protein) & $22.48 \pm 1.62$ & $23.05 \pm 1.50$ & $23.08 \pm 1.60$ & $22.39 \pm 1.50$ \\
\hline
\end{tabular}

Data are presented as the mean \pm SEM $\left(n=6 /\right.$ group) and were analyzed by Student's $t$ test (unpaired, two-tailed) between CTR and SD groups, and between VEH and CAF treatment group. ${ }^{*} p<0.01$.

Table 2. Caffeine contents in the SCN, midbrain, and plasma $3 \mathrm{~h}$ after intraperitoneal injection of vehicle or caffeine in early night

\begin{tabular}{lccc}
\hline Treatments & $\begin{array}{l}\text { SCN caffeine } \\
\text { (mmol/g protein) }\end{array}$ & $\begin{array}{l}\text { Midbrain caffeine } \\
\text { (mmol/g protein) }\end{array}$ & $\begin{array}{l}\text { Plasma caffeine } \\
\text { (mmol/ml) }\end{array}$ \\
\hline VEH & $26.50 \pm 14.02$ & $18.93 \pm 9.88$ & $0.028 \pm 0.02$ \\
CAF & $2691.54 \pm 722.35^{*}$ & $3180.69 \pm 212.37^{*}$ & $402.43 \pm 88.42^{*}$
\end{tabular}

Data are presented as the mean \pm SEM ( $n=6 /$ group) and were analyzed by Student's $t$ test (unpaired, two-tailed) between VEH and CAF treatment groups. ${ }^{*} p<0.002$.

\section{Discussion}

It is widely acknowledged that behavioral arousal in the usual rest period has the ability to reset the master circadian clock (Webb et al., 2014). For instance, 3 h of sleep deprivation in the middle of the rest period induced phase advances in Syrian hamsters (Antle and Mistlberger, 2000). Moreover, sleep deprivation and caffeine-induced arousal influence photic resetting of the SCN clock by attenuating light-induced phase shifts in nocturnal mice and hamsters (Mistlberger et al., 1997; Challet et al., 2001; Vivanco et al., 2013; van Diepen et al., 2014). Most of the experiments supporting these statements have been performed in laboratory rodents that are essentially night active. It remains unresolved, however, whether these nonphotic stimuli influence the SCN clock and its photic resetting of diurnal species in a similar or different manner. Using sleep deprivation and caffeine treatment as involuntary behavioral arousal, we show here that sleep deprivation in the early night induces phase delay, whereas both nightly sleep deprivation and caffeine treatment, whatever the time at which the animals are subjected to it, enhance lightinduced phase shifts in the diurnal Sudanian grass rat. These behavioral changes are concomitant at the cellular level with potentiation of light-induced c-Fos expression in SCN cells, in particular those containing calbindin. Noteworthy, these findings are conspicuously opposite to the results obtained earlier in nocturnal rodents, in which sleep deprivation and caffeine decrease light-induced phase shifts.

\section{Time course of sleep loss during sleep deprivation and after} caffeine treatments

In the present study, our sleep deprivation protocol significantly reduces sleep time and increases the time spent awake in both early and late subjective night. A previous study in grass rats (Hubbard et al., 2015) showed that $6 \mathrm{~h}$ of sleep deprivation, started at dark onset, significantly increased delta power during the next $3 \mathrm{~h}$ of sleep rebound. Our results indicate that following $4 \mathrm{~h}$ of sleep deprivation, wake duration in sleep-deprived animals went back to control levels and animals recovered sleep. We also showed that caffeine treatment $(30 \mathrm{mg} / \mathrm{kg})$ in early subjective night drastically increases wake timing during the $5 \mathrm{~h}$ period following the treatment. Midsubjective night treatment induces increased wake time during the $2 \mathrm{~h}$ post-treatment period. These results provide a detailed monitoring of behavioral arousal during sleep deprivation and after caffeine administration.
Sleep deprivation, but not caffeine, in the early night induces phase delays in diurnal grass rats

The phase-response curves for arousing stimuli show that both the magnitude and direction of the shifts are gated by circadian phase, with maximal phase advances during the middle of the rest period and minimal phase delays during the latter half of the usual wake phase (Hughes and Piggins, 2012; Webb et al., 2014). Experiments aimed at mimicking sleep deprivation by intracranial or intraperitoneal injection of an adenosine A1 agonist in the mid-sleeping period show dose-dependent shifts similar to those induced by sleep deprivation itself. In addition, the adenosine receptor antagonist caffeine attenuates the phase shifts produced by sleep deprivation in nocturnal rodents (Antle et al., 2001).

In the present study, we found that caffeine alone does not induce significant behavioral shifts in diurnal grass rats, which is in keeping with an earlier study in nocturnal rodents (Vivanco et al., 2013). In humans, however, caffeine intake in the early night produces a phase delay of the circadian melatonin phase (Burke et al., 2015). In parallel, sleep deprivation in early subjective night, without any notable hyperactivity, induces a phase delay of the behavioral rhythm in diurnal grass rats. Together, these data indicate that the overall shape and timing of phase responses to sleep deprivation in nocturnal and diurnal species depend on the phase of the rest/activity cycle and are phased at opposite circadian times in both categories of species.

\section{Sleep deprivation and caffeine treatment potentiate light-induced shifts in diurnal grass rats}

Arousing stimuli such as sleep deprivation, forced activity, or injections of an adenosine A1 agonist inhibit light-induced phase shifts (Watanabe et al., 1996; Mistlberger et al., 1997; Challet et al., 2001; Elliott et al., 2001; Sigworth and Rea, 2003). Sleep deprivation in mice attenuates the sustained response to light on SCN firing rate, while caffeine treatment normalizes the light response (van Diepen et al., 2014). Caffeine also blocks lightinduced phase delays in the mice (Vivanco et al., 2013).

We show here that $4 \mathrm{~h}$ of sleep deprivation in the early and late night enhances light-induced phase delays and advances in the diurnal grass rat. Furthermore, caffeine similarly potentiates lightinduced phase shifts. These findings are opposite to the reducing effects found in nocturnal rodents (Vivanco et al., 2013). In humans, however, caffeine intake in the early night does not significantly enhance the light-induced phase delay of the circadian melatonin phase (Burke et al., 2015). It is worth mentioning that the modulatory effects of sleep deprivation and caffeine on photic resetting in nocturnal and diurnal rodents are functionally comparable to those observed after serotonergic activation (Morin, 1999; Challet, 2007; Cuesta et al., 2008).

5-HT and adenosine levels in SCN and midbrain after sleep deprivation and caffeine treatment in the diurnal grass rats Since the activity of the central serotonergic and adenosinergic systems is closely related with behavioral arousal, they may 
participate in arousal-induced resetting of the SCN. Serotonin (5-HT) concentrations in the SCN follow a daily pattern, with higher levels occurring during the active phase in both nocturnal and diurnal rodents (Poncet et al., 1993; Cuesta et al., 2008). The increased concentration of 5-HT or its main metabolite 5-HIAA in the SCN and other hypothalamic areas during sleep deprivation was also correlated to circadian phase shifts and/or attenuated light-induced phase shifts in nocturnal rodents (Grossman et al., 2000; Challet et al., 2001). In the current experiment, 5-HT concentrations after $4 \mathrm{~h}$ of sleep deprivation as measured in tissue punches, remained unchanged in the SCN and midbrain of diurnal rodents, thus suggesting that arousal feedback would be mediated by other mediators (e.g., adenosinergic cues).

The adenosine receptor antagonist caffeine attenuates the phase advances induced by sleep deprivation and blocks lightinduced phase delays. In addition, microinjections of an adenosine agonist in the SCNs of hamsters and rats induce phase shifts, as does sleep deprivation, and attenuate light-induced phase shifts (Watanabe et al., 1996; Antle et al., 2001; Elliott et al., 2001). Some studies reported the presence of adenosine receptors in the SCN (Chen and van den Pol, 1997; Díaz-Muñoz et al., 1999; Hallworth et al., 2002), suggesting that caffeine may act directly on SCN cells. Ryanodine receptors (RyRs) are caffeine-sensitive $\mathrm{Ca}^{2+}$ release channels (McPherson et al., 1991). Caffeine-mediated increases of $\mathrm{Ca}^{2+}$ levels in SCN neurons are dependent on the activation of RyRs (Pfeffer et al., 2009). Ryanodine and caffeine treatments applied in vitro during the subjective day produce phase advances in the hamster SCN (Díaz-Muñoz et al., 1999). These findings indicate that the effects of sleep deprivation and in vivo caffeine treatment may be achieved by the activation of the adenosinergic system in the SCN. The present data do not fully support this hypothesis because adenosine levels in SCN and midbrain of grass rats, either sleep-deprived or treated with caffeine, remained essentially unchanged. On the other hand, tissue measurements do not accurately reflect release. Of note, while 5-HT and 5-HIAA levels remained unchanged in the SCN region, caffeine treatment in early night significantly increased 5-HT concentrations in the midbrain raphe. This confirms the fact that caffeine promotes serotonergic activation (Antle et al., 2001; Okada et al., 2001; Vivanco et al., 2013). Together, these findings suggest that arousal feedback may also be mediated by mediators other than serotonergic and adenosinergic pathways such as orexinergic, cholinergic, and glutamatergic cues (Klisch et al., 2009; Yamakawa and Antle, 2010; Belle et al., 2014; Yamakawa et al., 2016). Further studies using intracerebral microdialysis of 5-HT, adenosine, orexin, glutamate, and acetylcholine receptor agonists are needed to solve this issue.

\section{Cellular responses of arousal on light sensitivity of SCN}

Nocturnal and diurnal species display similar temporal patterns of light-induced c-Fos expression in the SCN (Mahoney et al., 2001). Photic stimulation of c-Fos expression in the SCN has been used by many laboratories to study the photosensitive phase of the master clock. Previous studies in nocturnal species have shown that levels of c-Fos expression in the SCN decrease when they are aroused during their usual resting period (Mistlberger et al., 1998; Antle and Mistlberger, 2000; Dattolo et al., 2016). Activation of the adenosine A1 receptor attenuates light-induced c-Fos and phosphorylated ERK expression in the SCN (Watanabe et al., 1996; Sigworth and Rea, 2003). Our results in the diurnal grass rat show that sleep deprivation in the early night increases light-induced c-Fos induction in the ventral SCN. Caf- feine treatment in the mid-night period induces c-Fos expression in the dorsal SCN, albeit without inducing a subsequent phase shift. Furthermore, caffeine treatment in both early night and mid-night periods potentiated light-induced c-Fos expression in the ventral SCN. These data show that the feedback effects of arousal on SCN cellular activity and their interaction with the light-induced expression of immediate early genes are opposite in nocturnal and diurnal rodents.

Our double immunolabeling indicates that behavioral arousal activates a large proportion of calbindin-containing cells in the SCN of diurnal rodents. Earlier studies in hamsters have already shown a role for SCN calbindin in the maintenance of circadian rhythms and photic entrainment (Hamada et al., 2003; Kriegsfeld et al., 2008; Stadler et al., 2010). Our results are the first to suggest that SCN calbindin-containing cells could be involved in the feedback effect of arousal on the master clock and its light-induced phase shifts also in diurnal species.

To sum up, the present study in a diurnal rodent reveals that sleep deprivation can phase delay the master clock and that both sleep deprivation and caffeine administration potentiate light-induced phase shifts. This work reinforces the view that modulation of the SCN clock by arousing cues may be a key function to maintain the respective temporal niche in day-active and night-active species. Moreover, the availability of a diurnal rodent model could be useful not only for comparative studies with nocturnal rodents and reciprocal interactions with human circadian research, but also for biomedical applications.

\section{References}

Albrecht U, Sun ZS, Eichele G, Lee CC (1997) A differential response of two putative mammalian circadian regulators, mper 1 and mper2, to light. Cell 91:1055-1064. CrossRef Medline

Antle MC, Mistlberger RE (2000) Circadian clock resetting by sleep deprivation without exercise in the Syrian hamster. J Neurosci 20:9326-9332. Medline

Antle MC, Steen NM, Mistlberger RE (2001) Adenosine and caffeine modulate circadian rhythms in the Syrian hamster. Neuroreport 12:29012905. CrossRef Medline

Belle MD, Hughes AT, Bechtold DA, Cunningham P, Pierucci M, Burdakov D, Piggins HD (2014) Acute suppressive and long-term phase modulation actions of orexin on the mammalian circadian clock. J Neurosci 34:3607-3621. CrossRef Medline

Bourdeaux R, Desor D, Lehr PR, Younos C, Capolaghi B (1998) Effects of fluoxetine and norfluoxetine on 5-hydroxytryptamine metabolism in blood platelets and brain after administration to rats. J Pharm Pharmacol 50:1387-1392. CrossRef Medline

Burke TM, Markwald RR, McHill AW, Chinoy ED, Snider JA, Bessman SC, Jung CM, O'Neill JS, Wright KP Jr (2015) Effects of caffeine on the human circadian clock in vivo and in vitro. Sci Transl Med 7:305ral46. CrossRef Medline

Caccia S, Anelli M, Codegoni AM, Fracasso C, Garattini S (1993) The effects of single and repeated anorectic doses of 5-hydroxytryptamine uptake inhibitors on indole levels in rat brain. Br J Pharmacol 110:355-359. CrossRef Medline

Caldelas I, Poirel VJ, Sicard B, Pévet P, Challet E (2003) Circadian profile and photic regulation of clock genes in the suprachiasmatic nucleus of a diurnal mammal Arvicanthis ansorgei. Neuroscience 116:583-591. CrossRef Medline

Challet E (2007) Minireview: entrainment of the suprachiasmatic clockwork in diurnal and nocturnal mammals. Endocrinology 148:5648-5655. CrossRef Medline

Challet E, Pévet P (2003) Interactions between photic and nonphotic stimuli to synchronize the master circadian clock in mammals. Front Biosci 8:s246-s257. CrossRef Medline

Challet E, Turek FW, Laute M, Van Reeth O (2001) Sleep deprivation decreases phase-shift responses of circadian rhythms to light in the mouse: role of serotonergic and metabolic signals. Brain Res 909:81-91. CrossRef Medline 
Chen G, van den Pol AN (1997) Adenosine modulation of calcium currents and presynaptic inhibition of GABA release in suprachiasmatic and arcuate nucleus neurons. J Neurophysiol 77:3035-3047. Medline

Cuesta M, Mendoza J, Clesse D, Pévet P, Challet E (2008) Serotonergic activation potentiates light resetting of the main circadian clock and alters clock gene expression in a diurnal rodent. Exp Neurol 210:501513. CrossRef Medline

Daan S, Pittendrigh CS (1976) Functional analysis of circadian pacemakers in nocturnal rodents. 2. Variability of phase response curves. J Comp Physiol A 106:253-266. CrossRef

Dattolo T, Coomans CP, van Diepen HC, Patton DF, Power S, Antle MC, Meijer JH, Mistlberger RE (2016) Neural activity in the suprachiasmatic circadian clock of nocturnal mice anticipating a daytime meal. Neuroscience 315:91-103. CrossRef Medline

Díaz-Muñoz M, Dent MA, Granados-Fuentes D, Hall AC, Hernández-Cruz A, Harrington ME, Aguilar-Roblero R (1999) Circadian modulation of the ryanodine receptor type 2 in the SCN of rodents. Neuroreport 10:481486. CrossRef Medline

Elliott KJ, Todd Weber E, Rea MA (2001) Adenosine A1 receptors regulate the response of the hamster circadian clock to light. Eur J Pharmacol 414:45-53. CrossRef Medline

Grossman GH, Mistlberger RE, Antle MC, Ehlen JC, Glass JD (2000) Sleep deprivation stimulates serotonin release in the suprachiasmatic nucleus. Neuroreport 11:1929-1932. CrossRef Medline

Hallworth R, Cato M, Colbert C, Rea MA (2002) Presynaptic adenosine A1 receptors regulate retinohypothalamic neurotransmission in the hamster suprachiasmatic nucleus. J Neurobiol 52:230-240. CrossRef Medline

Hamada T, LeSauter J, Lokshin M, Romero MT, Yan L, Venuti JM, Silver R (2003) Calbindin influences response to photic input in suprachiasmatic nucleus. J Neurosci 23:8820-8826. Medline

Hubbard J, Ruppert E, Calvel L, Robin-Choteau L, Gropp CM, Allemann C, Reibel S, Sage-Ciocca D, Bourgin P (2015) Arvicanthis ansorgei, a novel model for the study of sleep and waking in diurnal rodents. Sleep 38:979988. CrossRef Medline

Hughes AT, Piggins HD (2012) Feedback actions of locomotor activity to the circadian clock. Prog Brain Res 199:305-336. CrossRef Medline

Jha PK, Challet E, Kalsbeek A (2015) Circadian rhythms in glucose and lipid metabolism in nocturnal and diurnal mammals. Mol Cell Endocrinol 418:74-88. CrossRef Medline

Klisch C, Inyushkin A, Mordel J, Karnas D, Pévet P, Meissl H (2009) Orexin A modulates neuronal activity of the rodent suprachiasmatic nucleus in vitro. Eur J Neurosci 30:65-75. CrossRef Medline

Kriegsfeld LJ, Mei DF, Yan L, Witkovsky P, Lesauter J, Hamada T, Silver R (2008) Targeted mutation of the calbindin D28K gene disrupts circadian rhythmicity and entrainment. Eur J Neurosci 27:2907-2921. CrossRef Medline

Mahoney MM, Nunez AA, Smale L (2000) Calbindin and Fos within the suprachiasmatic nucleus and the adjacent hypothalamus of Arvicanthis niloticus and Rattus norvegicus. Neuroscience 99:565-575. CrossRef Medline

Mahoney M, Bult A, Smale L (2001) Phase response curve and light-induced fos expression in the suprachiasmatic nucleus and adjacent hypothalamus of Arvicanthis niloticus. J Biol Rhythms 16:149-162. CrossRef Medline

McPherson PS, Kim YK, Valdivia H, Knudson CM, Takekura H, FranziniArmstrong C, Coronado R, Campbell KP (1991) The brain ryanodine receptor: a caffeine-sensitive calcium release channel. Neuron 7:17-25. CrossRef Medline

Mistlberger RE, Landry GJ, Marchant EG (1997) Sleep deprivation can attenuate light-induced phase shifts of circadian rhythms in hamsters. Neurosci Lett 238:5-8. CrossRef Medline

Mistlberger RE, Bossert JM, Holmes MM, Marchant EG (1998) Serotonin and feedback effects of behavioral activity on circadian rhythms in mice. Behav Brain Res 96:93-99. CrossRef Medline
Mohawk JA, Green CB, Takahashi JS (2012) Central and peripheral circadian clocks in mammals. Annu Rev Neurosci 35:445-462. CrossRef Medline

Morin LP (1999) Serotonin and the regulation of mammalian circadian rhythmicity. Ann Med 31:12-33. CrossRef Medline

Mrosovsky N (1996) Locomotor activity and non-photic influences on circadian clocks. Biol Rev Camb Philos Soc 71:343-372. CrossRef Medline

Mrosovsky N, Edelstein K, Hastings MH, Maywood ES (2001) Cycle of period gene expression in a diurnal mammal (Spermophilus tridecemlineatus): implications for nonphotic phase shifting. J Biol Rhythms 16:471-478. CrossRef Medline

Okada M, Nutt DJ, Murakami T, Zhu G, Kamata A, Kawata Y, Kaneko S (2001) Adenosine receptor subtypes modulate two major functional pathways for hippocampal serotonin release. J Neurosci 21:628-640. Medline

Pfeffer M, Müller CM, Mordel J, Meissl H, Ansari N, Deller T, Korf HW, von Gall C (2009) The mammalian molecular clockwork controls rhythmic expression of its own input pathway components. J Neurosci 29:61146123. CrossRef Medline

Poncet L, Denoroy L, Jouvet M (1993) Daily variations in in vivo tryptophan hydroxylation and in the contents of serotonin and 5-hydroxyindoleacetic acid in discrete brain areas of the rat. J Neural Transm Gen Sect 92:137-150. CrossRef Medline

Refinetti R (2006) Circadian physiology. In Circadian physiology, Ed 2 (Refinetti R, Ed), p 667. Boca Raton, FL: CRC Taylor and Francis.

Shearman LP, Sriram S, Weaver DR, Maywood ES, Chaves I, Zheng B, Kume K, Lee CC, van der Horst GT, Hastings MH, Reppert SM (2000) Interacting molecular loops in the mammalian circadian clock. Science 288 : 1013-1019. CrossRef Medline

Sigworth LA, Rea MA (2003) Adenosine A1 receptors regulate the response of the mouse circadian clock to light. Brain Res 960:246-251. CrossRef Medline

Slotten HA, Krekling S, Pévet P (2005) Photic and nonphotic effects on the circadian activity rhythm in the diurnal rodent Arvicanthis ansorgei. Behav Brain Res 165:91-97. CrossRef Medline

Smale L, Lee T, Nunez AA (2003) Mammalian diurnality: some facts and gaps. J Biol Rhythms 18:356-366. CrossRef Medline

Stadler F, Schmutz I, Schwaller B, Albrecht U (2010) Lack of calbindinD28k alters response of the murine circadian clock to light. Chronobiol Int 27:68-82. CrossRef Medline

van Diepen HC, Lucassen EA, Yasenkov R, Groenen I, Ijzerman AP, Meijer JH, Deboer T (2014) Caffeine increases light responsiveness of the mouse circadian pacemaker. Eur J Neurosci 40:3504-3511. CrossRef Medline

Vivanco P, Studholme KM, Morin LP (2013) Drugs that prevent mouse sleep also block light-induced locomotor suppression, circadian rhythm phase shifts and the drop in core temperature. Neuroscience 254:98-109. CrossRef Medline

Watanabe A, Moriya T, Nisikawa Y, Araki T, Hamada T, Shibata S, Watanabe S (1996) Adenosine Al-receptor agonist attenuates the light-induced phase shifts and fos expression in vivo and optic nerve stimulationevoked field potentials in the suprachiasmatic nucleus in vitro. Brain Res 740:329-336. CrossRef Medline

Webb IC, Antle MC, Mistlberger RE (2014) Regulation of circadian rhythms in mammals by behavioral arousal. Behav Neurosci 128:304325. CrossRef Medline

Yamakawa GR, Antle MC (2010) Phenotype and function of raphe projections to the suprachiasmatic nucleus. Eur J Neurosci 31:1974-1983. CrossRef Medline

Yamakawa GR, Basu P, Cortese F, MacDonnell J, Whalley D, Smith VM, Antle MC (2016) The cholinergic forebrain arousal system acts directly on the circadian pacemaker. Proc Natl Acad Sci U S A 113:13498-13503. CrossRef Medline 